A Gollahorative Fight

\title{
against Gancer
}

Also in this issue:

- Predicting the Spread of Airborne Hazards

- Climate and Its Effect on California Agriculture

- New Paths to Extreme Conditions

- Teller's Legacy in Shock Physics

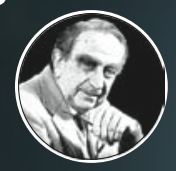




\section{About the Cover}

In an ongoing partnership between Lawrence Livermore and the University of California (UC) Davis Cancer Center, researchers are adapting existing technologies to detect the early stages of cancer and tailor treatment for cancer patients. The article beginning on p. 4 describes recent successes from the collaborative effort. On the cover, the center's director, Ralph deVere White (left), and a colleague work in the operating room. The rendering in the bottom right corner shows an isocentric proton-beam system being developed at Livermore for cancer treatment. The vertical column above the patient is a proton accelerator that revolves around an axis passing through the center of the area to be treated. (Photograph courtesy of UC Davis Cancer Center. Artist's rendering by Steve Hawkins.)

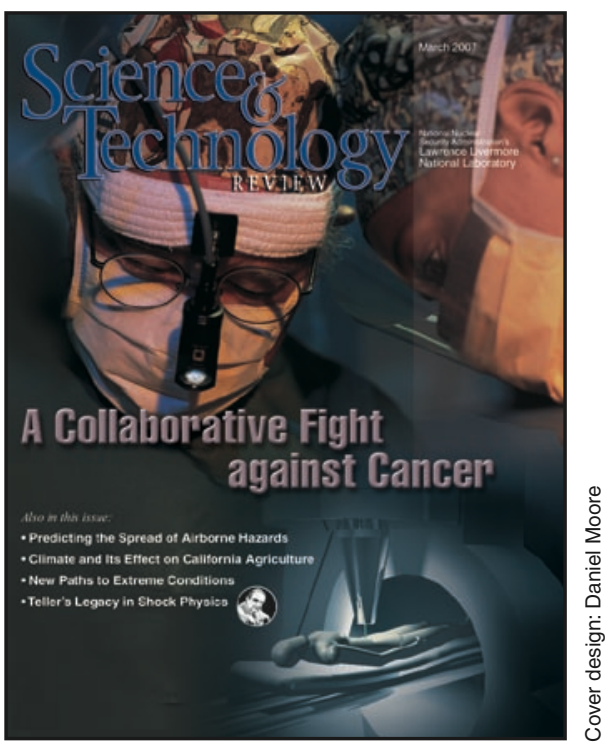

\section{About the Review}

Lawrence Livermore National Laboratory is operated by the University of California for the Department of Energy's National Nuclear Security Administration. At Livermore, we focus science and technology on ensuring our nation's security. We also apply that expertise to solve other important national problems in energy, bioscience, and the environment. Science \& Technology Review is published 10 times a year to communicate, to a broad audience, the Laboratory's scientific and technological accomplishments in fulfilling its primary missions. The publication's goal is to help readers understand these accomplishments and appreciate their value to the individual citizen, the nation, and the world.

Please address any correspondence (including name and address changes) to $S \& T R$, Mail Stop L-664, Lawrence Livermore National Laboratory, P.O. Box 808, Livermore, California 94551, or telephone (925) 423-3432. Our e-mail address is str-mail@llnl.gov. $S \& T R$ is available on the World Wide Web at www.llnl.gov/str.

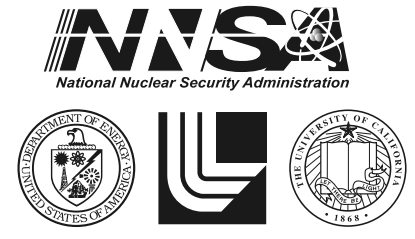

Prepared by LLNL under Contract No. W-7405-Eng-48
(C) 2007. The Regents of the University of California. All rights reserved. This document has been authored by the Regents of the University of California under Contract No. W-7405-Eng-48 with the U.S. Government. To request permission to use any material contained in this document, please submit your request in writing to Library Report Orders, Lawrence Livermore National Laboratory, Mail Stop L-610, P.O. Box 808, Livermore, California 94551, or to our e-mail address report-orders@1lnl.gov.

This document was prepared as an account of work sponsored by an agency of the United States Government. Neither the United States Government nor the University of California nor any of their employees makes any warranty, expressed or implied, or assumes any legal liability or responsibility for the accuracy, completeness, or usefulness of any information, apparatus, product, or process disclosed, or represents that its use would not infringe privately owned rights. Reference herein to any specific commercial product, process, or service by trade name, trademark, manufacturer, or otherwise, does not necessarily constitute or imply its endorsement, recommendation, or favoring by the United States Government or the University of California. The views and opinions of authors expressed herein do not necessarily state or reflect those of the United States Government or the University of California and shall not be used for advertising or product endorsement purposes. 


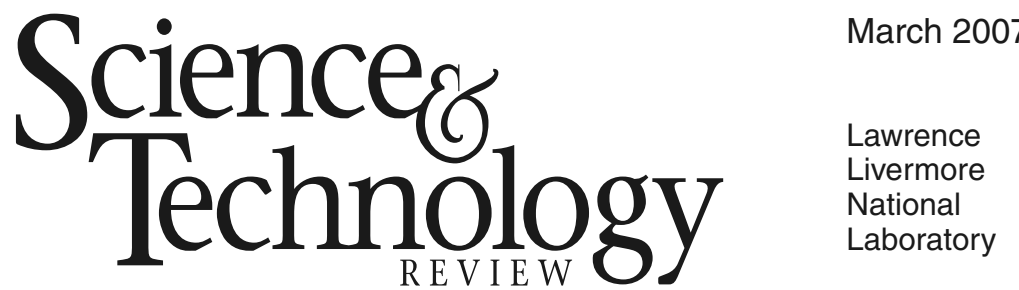

\section{S\&TR Staff}

\section{SCIENTIFIC Editor}

Harry B. Radousky

\section{Managing Editor}

Ray Marazzi

Publication Editor

Carolin Middleton

\section{WrITERS}

Arnie Heller, Ann Parker, Gabriele

Rennie, Maurina S. Sherman, and

Katie Walter

\section{Art Director}

Daniel Moore

\section{Designers}

Alexandria A. Ballard and Daniel Moore

ILLUSTRATOR

Sabrina Fletcher

Proofreader

Pamela MacGregor

$S \& T R$, a Director's Office publication, is produced by the Technical Information Department under the direction of the Office of Policy, Planning, and Special Studies.

\section{$S \& T R$ is available on the Web} at www.llnl.gov/str.

Printed in the United States of America

\section{Available from}

National Technical Information Service

U.S. Department of Commerce

5285 Port Royal Road

Springfield, Virginia 22161

\section{UCRL-TR-52000-07-3}

Distribution Category UC-99

March 2007

\section{Contents}

\section{Features}

3 Partnering to Enhance Americans' Health

Commentary by Tomás Díaz de la Rubia

4 Advancing the Frontiers in Cancer Research

Researchers at the University of California Davis Cancer

Center and Lawrence Livermore are teaming up to fight cancer.

12 On the Leading Edge of Atmospheric Predictions

Continual research and development at the National

Atmospheric Release Advisory Center help mitigate the consequences of toxic airborne hazards.

\section{Research Highlights}

20 Climate and Agriculture: Change Begets Change A Livermore researcher is using computer models to explore how a warmer climate may affect crop yields in California.

\section{New Routes to High Temperatures and Pressures}

With functionally graded density impactors composed of thin metal and polyethylene films, researchers can explore new areas of experimental physics.

\section{Teller Centennial Highlight}

\section{From Sound Waves to Stars: Teller's Contributions} to Shock Physics

Edward Teller's interest in shock physics led to significant developments in both basic and applied science.

\section{Departments}

\section{The Laboratory in the News}

\section{Patents and Awards}

\section{Abstracts}




\section{Comet's dust is a mixed bag of the entire solar system}

Livermore researchers, along with hundreds of investigators worldwide, are uncovering the mysteries underlying the history of our solar system through analysis of comet dust gathered from the Stardust mission that returned to Earth in January 2006. A series of research articles associated with the space dust appears in the December 15, 2006, issue of Science.

Stardust, which launched in 1999 to rendezvous with Comet Wild 2 in 2004, captured less than 1 milligram of the comet's particulate material. However, this miniscule amount has been enough for Livermore scientists to determine the composition of the tiny particles.

Using the most powerful microscope in the world, Livermore's SuperSTEM (scanning transmission electron microscope), researchers were surprised to find osbornite among the Wild 2 dust. Osbornite forms much closer to the Sun than where Wild 2 spent most of its life - outside the orbit of Neptune. Further analysis revealed a mix of silicates, sulfides, and organic matter, all of which represent material that has been scattered across the solar system. The research indicates that the early solar system was a volatile place in which materials may have been ejected from the inner regions and relocated to the outer regions.

Contact: John Bradley (925) 423-0666 (bradley33@IInl.gov).

\section{Hawaiian corals may be older than previously believed}

Researchers from Lawrence Livermore, Stanford University, the University of California (UC) at Berkeley, and UC Santa Cruz have determined that three groups of Hawaiian deep-sea corals grow more slowly and are far older than previously believed. Their research appeared in the December 7, 2006, issue of Marine Ecology Progress Series.

Using radiocarbon dating techniques, scientists calculated radial growth rates on specimens of Corallium secundum, Gerardia sp., and Leiopathes glaberrima, which were collected from the Makapuu deep-sea coral bed off the southeast coast of Oahu. Results showed that Gerardia sp. fossils, or gold corral, had radial growth rates of 14 to 45 micrometers per year and ages ranging from 450 to 2,742 years. Similarly, the scientists found that L. glaberrima, or black coral, is extremely long-lived with a growth rate less than 10 micrometers per year and a life span of around 2,380 years. By contrast, measurements on black coral samples taken near Lahaina, Maui, yielded growth rates ranging from 130 to 1,140 micrometers per year and life spans between 12 and 32 years.

Interest in the ecology and biology of deep-sea corals is increasing in response to the threat of their physical destruction, which is due, in part, to both commercial deep-sea fishing and climate change. Data from deep-sea corals also provide a valuable record of past climate and environmental change.

Contact: Tom Guilderson (925) 422-1753 (tguilderson@IInl.gov).

\section{Proteins involved in growth of plague bacterium}

Researchers from Lawrence Livermore and Pacific Northwest national laboratories have re-created growth conditions in flea carriers and mammalian hosts to uncover 89 proteins and 87 likely proteins in Yersinia pestis, the bacterium that caused the Black Death plagues. The study indicates that the abundance of these proteins changes relative to the bacterium's virulence.

The team, led by Livermore scientists Sandra McCutchenMaloney and Brett Chromy of the Chemistry, Materials, and Life Sciences Directorate, reports its findings in the November 2006 issue of Journal of Proteome Research. The study, which was funded by the Department of Homeland Security, identified the proteins as "unique biomarkers related specifically to growth condition." Biomarkers associated with disease progression show promise as detection tools in public health and biodefense and can guide drug and vaccine designers in their quest to disrupt the microbe's ability to infect. Fleas are vectors for the disease and can spread it to rodent and human hosts.

The paper follows up on a previous Livermore study investigating the proteome of $Y$. pestis under these same growth conditions. Both studies used comparative proteomics techniques to home in on differentially expressed proteins under conditions that represent key virulence regulators in Y. pestis. The earlier study used a gel-based screen to show the proteins, whereas the current study used a mass spectrometry-based screen. Together, these two technologies can examine a larger portion of the proteome and identify the key proteins involved in regulating virulence.

Contact: Brett Chromy (925) 422-2454 (chromy1@IInl.gov) or Sandra McCutchen-Maloney (925) 423-5065 (smaloney@IInl.gov). 


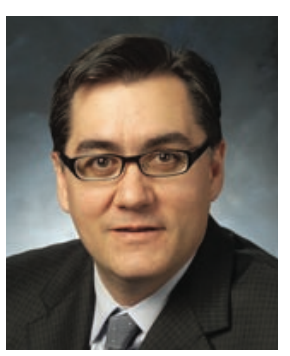

\section{Partnering to Enhance Americans' Health}

ARTNERSHIPS have played a major role at Lawrence

Livermore since the Laboratory's establishment in 1952. Working with government, industrial, and academic partners helps us accomplish our programmatic goals more efficiently, strengthens our scientific research efforts, and provides capabilities not available at Livermore. These joint efforts come in many forms, from strategic alliances to commercial licensing agreements for Livermore technologies to ad hoc academic collaborations.

One of the Laboratory's most fruitful partnerships has been with the University of California (UC) Davis Cancer Center. In the late 1990s, scientists in the Physics Directorate under the direction of Dennis Matthews and in the Biology and Biotechnology Research Program Directorate under Kenneth Turteltaub were seeking clinical partners to further develop emerging technologies with potential health-care applications. Matthews's team wanted to use lasers as a noninvasive medical diagnostic, for example, to discover tumors and image cancer cells. Turteltaub's team sought to apply the technologies available at Livermore's Center for Accelerator Mass Spectrometry to develop individualized molecular treatments in such areas as toxicology and pharmacokinetics. At the same time, Ralph deVere White, an oncologist, surgeon, and director of the UC Davis Cancer Center, was looking for new technologies to improve cancer diagnosis and treatment.

These three scientists organized a meeting between UC Davis clinical and basic biologists and scientists from several Livermore directorates. The advantages of a partnership became clear immediately, and a number of alliances were formed. A memorandum of understanding between the two institutions formalized the relationship in August 2001.

As part of the partnership, Matthews was named associate director for medical technology at the UC Davis Cancer Center, and Livermore molecular biologist and cancer expert Jim Felton became associate director for cancer control. Turteltaub also joined the center, becoming a coleader for the Molecular Oncology Program. Since July 2002, the UC Davis Cancer Center has been a National Cancer Institute (NCI) designated center, 1 of 61 centers in the U.S. and the ninth in California. It also is the first designated cancer center to partner with a Department of Energy national laboratory, a relationship that draws positive comments from NCI peer reviewers.

The Livermore-UC Davis partnership has led to many healthcare-related applications for existing Livermore technologies. Some of these efforts, such as the small proton accelerator developed for cancer therapy, and the time-of-flight secondaryion mass spectrometer used for molecular imaging of cells, are featured in the article beginning on p. 4. Many more joint projects are ongoing. In one promising effort, researchers are designing synthetic antibodies with radiotherapy agents to identify tumor cells. Another project is using bioaerosol mass spectroscopy to detect lung cancer in its early stage. Livermore scientists are also developing techniques to examine the growth mechanisms of tumors and to detect low-level calcium uptake and loss in bone.

Currently, about 25 Livermore researchers have joint projects with the UC Davis Cancer Center. In almost every case, they are adapting technologies first developed for stockpile stewardship, biodefense, environmental cleanup, and other DOE mission areas for use in cancer research. The partnership is a striking example of how science and technology developed at a national security laboratory can be used to meet other enduring national needs.

Research at the intersection of biology, national security, energy security, and health will continue to deliver important contributions to society. For example, biologically inspired solutions for national security problems, such as technologies to counter possible bioterrorist threats, may help to prevent a natural pandemic as well. In 2006, recognizing the importance of these intersecting research areas, Laboratory Director George Miller announced the merger of two long-time directorates - combining Biosciences with Chemistry and Materials Science. The new directorate, called Chemistry, Materials, and Life Sciences, will foster collaborative efforts in these vital areas and continue to look for national security technologies that can also improve the nation's health care, including cancer research and treatment.

Tomás Díaz de la Rubia is associate director for Chemistry, Materials, and Life Sciences. 


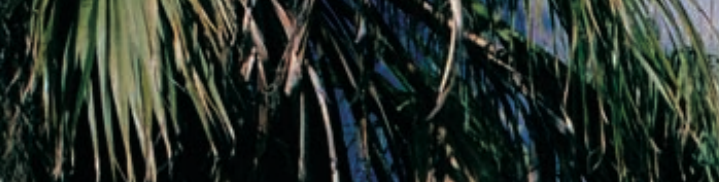

(1)

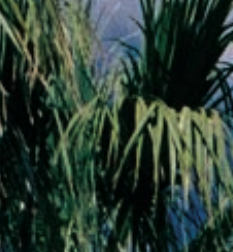

in Fanther

Livermore technologies are

- being adapted to characterize

cancer cells and provide new

- xireatinent methods.

? 3

$\frac{1}{2}+\frac{1}{x+2}$

LIA Nonfor
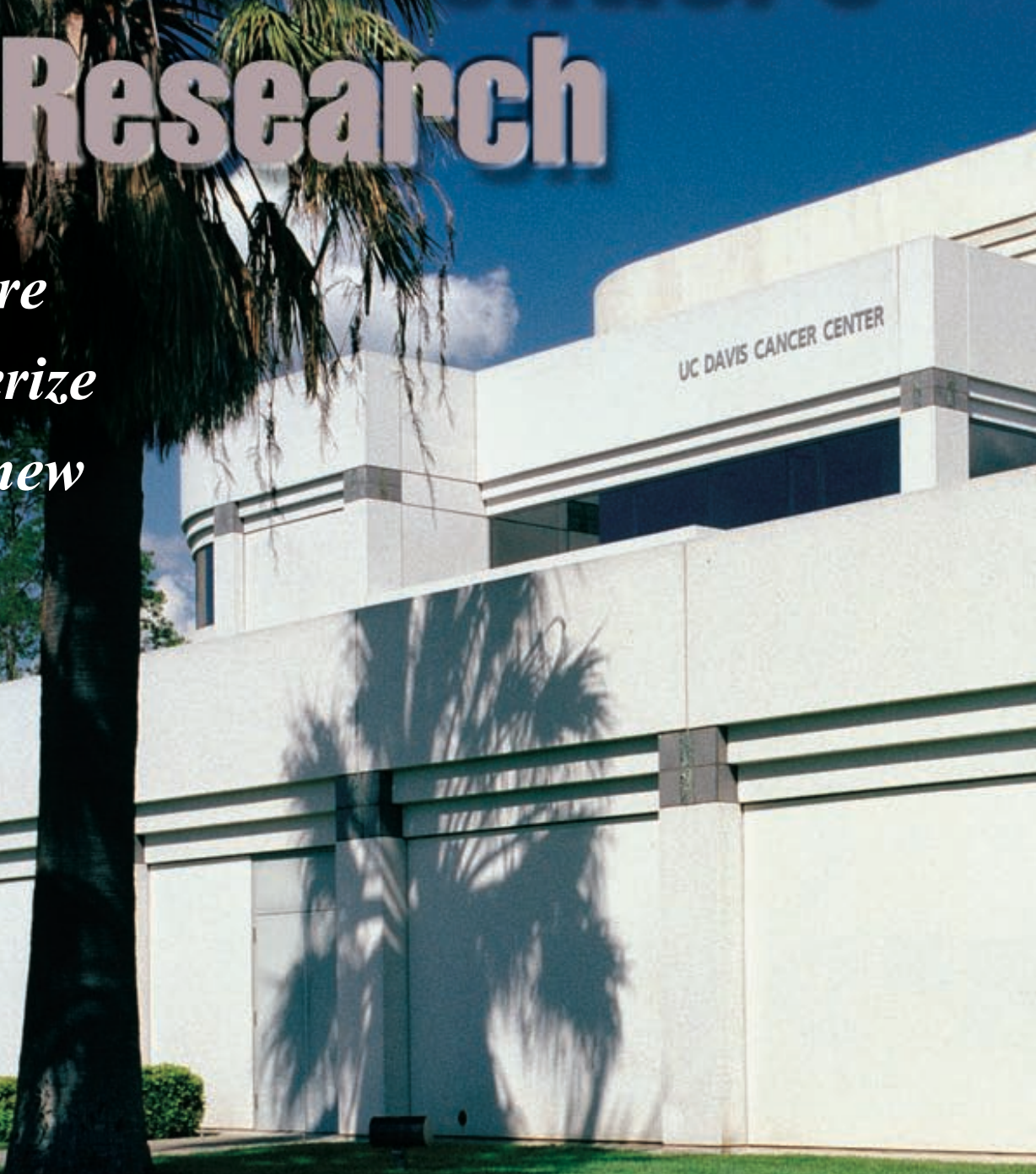
M LLIONS of cell duplications occur in our bodies each day. As an essential part of this process, the nucleotides that make up the DNA fingerprint - adenine, guanine, cytosine, and thymine - are reproduced with perfect fidelity. Occasionally,

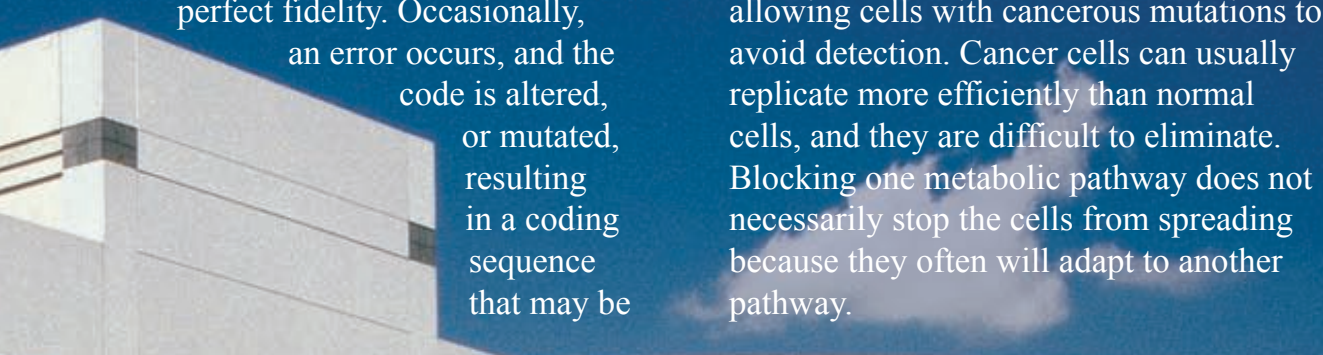

expressed as an abnormal cell. Typically, the body's cellular machinery repairs these DNA mistakes, or its immune system disposes of the aberrant cells. With cancer, however, something in the genetic coding turns off the body's immune mechanisms, allowing cells with cancerous mutations to avoid detection. Cancer cells can usually replicate more efficiently than normal cells, and they are difficult to eliminate. Blocking one metabolic pathway does not necessarily stop the cells from spreading because they often will adapt to another
Cancer includes hundreds of diseases, each with a specific pattern of behavior and genetic makeup. No universal method can treat the many different types. Some cancers require surgery, while others are best treated with radiation, chemotherapy, or a combination of the two. To determine the best therapy for each patient, physicians need diagnostic tools that can detect the disease in its early stages and predict its course. But current technologies do not allow clinicians to precisely design individualized treatments. In addition, those who are treating cancer patients often are not aware of emerging technologies that could be useful.

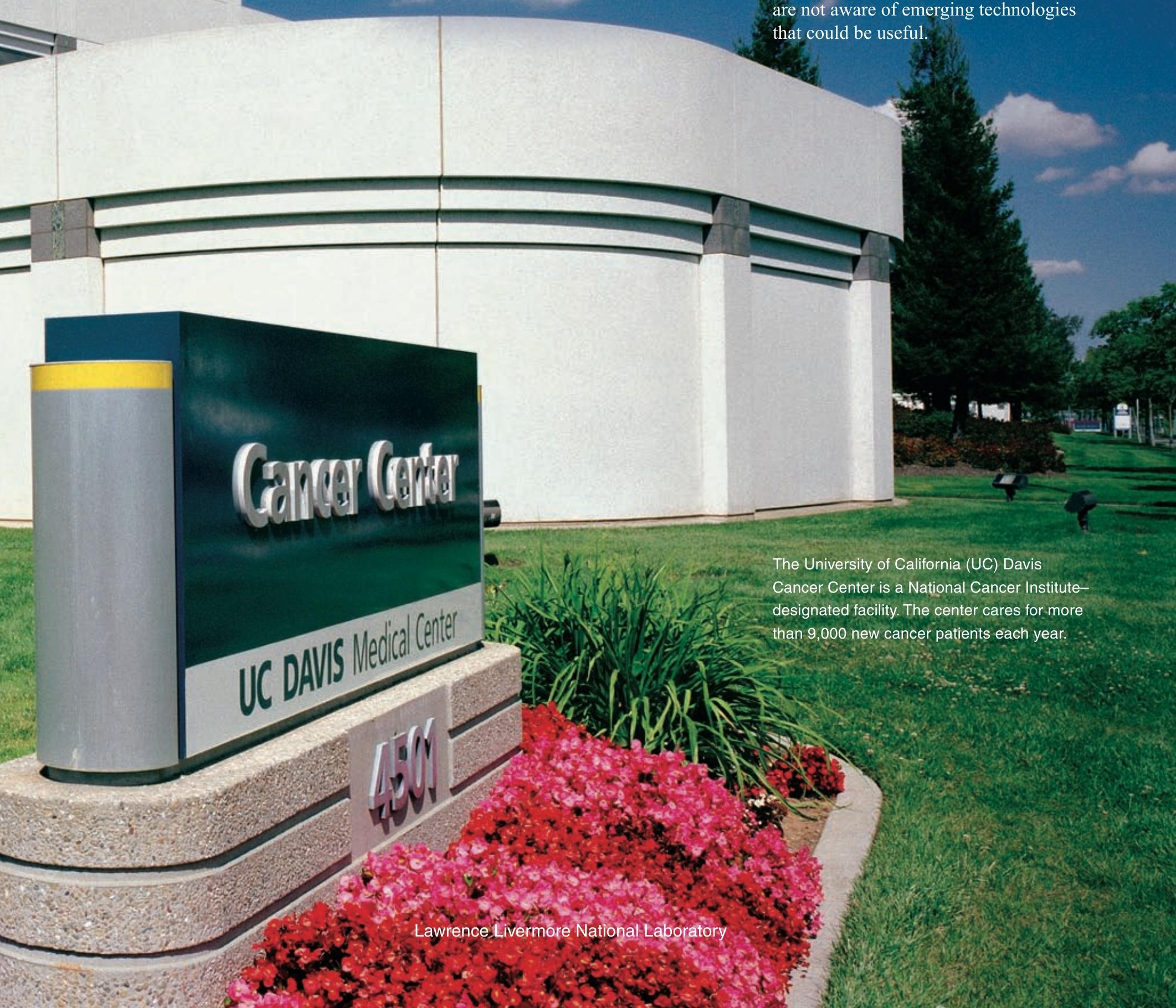


After many collaborations between Lawrence Livermore and the University of California (UC) Davis Cancer Center, researchers at both institutions began realizing that a formal partnership could help advance cancer research and make new treatment options available. The Laboratory's advanced mass spectrometers, lasers, computational codes, and other instruments originally developed as national security technologies offered potential medical solutions.

\section{Powerful Instruments Aid Research}

In 2000, Lawrence Livermore and the UC Davis Cancer Center formed a strategic collaboration, combining UC Davis's clinical expertise and basic science research resources with Livermore's technologies. This collaboration represents the first time a major U.S. cancer center has teamed with a national laboratory, and the joint effort helped the center become a designated National Cancer Institute facility in July 2002. The partnership involves more than 200 physicians, molecular biologists, pharmacologists, physicists, chemists, and cell biologists. Physicians and laboratory clinicians work together to develop new cancer therapies, detection methods, and prevention strategies. (See $S \& T R$, April 2001,

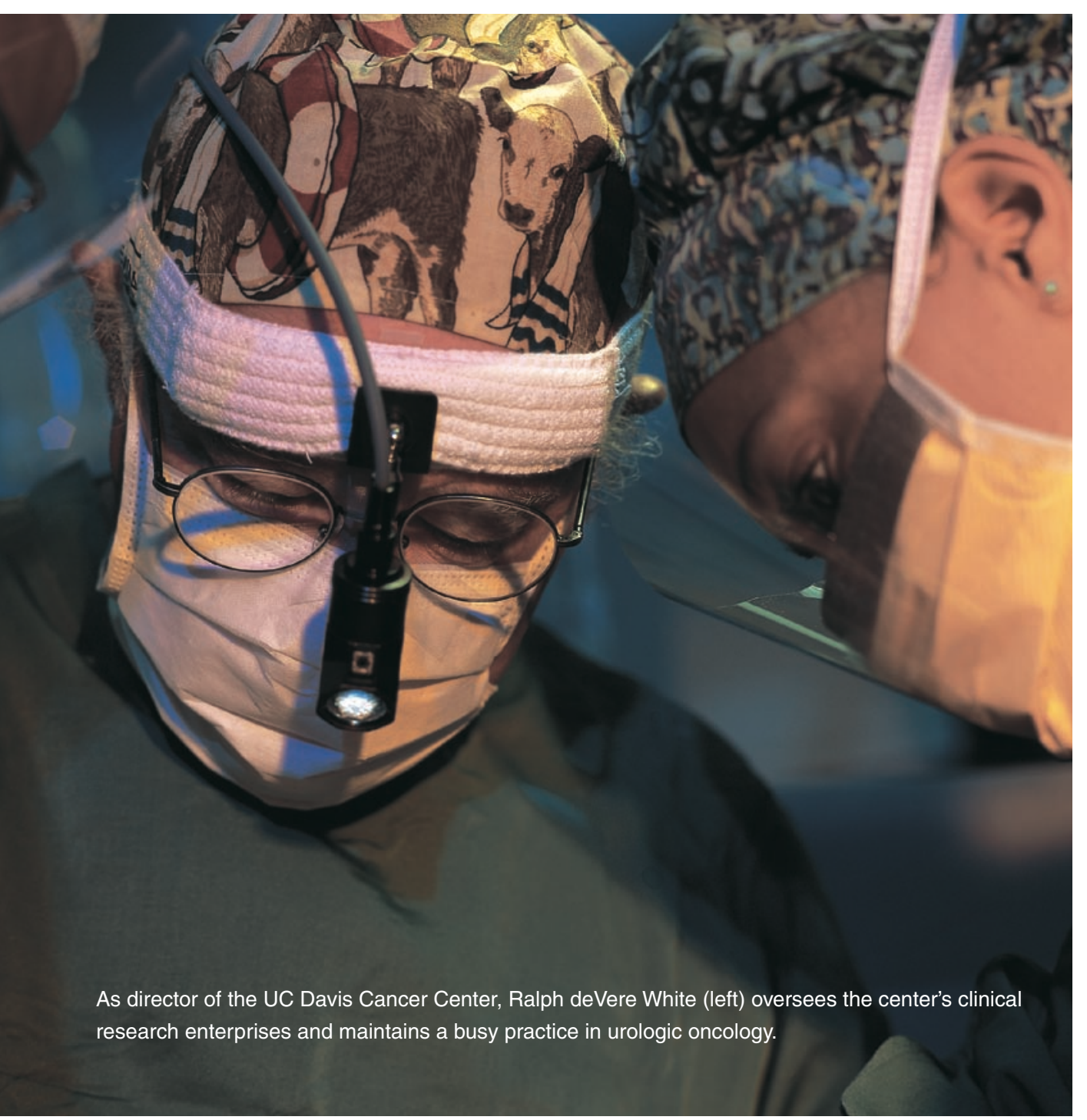

pp. 15-17.) Current efforts include adapting time-of-flight mass spectrometry to characterize individual cancer cells, using accelerator mass spectrometry (AMS) to tailor cancer therapy, and developing a proton accelerator to zap cancer cells.

Molecular biologist Jim Felton, a specialist in cancer causation and prevention, serves as an associate director for the Cancer Etiology, Prevention, and Control Program at the UC Davis Cancer Center. "In addition to its clinical expertise, UC Davis has a strong program in the molecular biology of cancer," says Felton, who works in Livermore's Chemistry, Materials, and Life Sciences (CMLS) Directorate. "We have instruments they can exploit." For example, prior to the collaboration, few clinicians knew that AMS could be used to monitor a drug as it metabolizes, that lasers could provide a noninvasive approach to detect cancer, or that computational models could save time by predicting experimental outcomes.

The UC Davis Cancer Center is organized into six programs: molecular oncology; cancer biology in animals; developmental therapeutics; cancer etiology, prevention, and control; prostate cancer; and biomedical technology. Biologist Ken Turteltaub of CMLS serves as an associate director of shared resources, and Dennis Matthews, director of the Laboratory's Center for Biotechnology, Biophysical Sciences, and Bioengineering, is an associate director of biomedical technology. Matthews and Felton help identify Livermore technologies that could be relevant to cancer research. Matthews says, "No other cancer center in the world has a dedicated biotechnologies program."

At the heart of the center is its director, Ralph deVere White, associate dean for cancer programs and a urologic oncologist who has researched bladder and prostate cancer for more than 20 years. As director, he oversees the center's many projects, 
which include research for early cancer diagnosis, individualized therapy, and improved radiation treatment.

\section{Early Identification of Cell Changes}

Analyzing a single change in a protein or gene does not provide enough information to predict the seriousness of a cancer or how the disease will progress. Physicians must interpret a large number of clinical variables that together suggest the most likely course of the disease. In particular, they look for the potential end points of disease progression, such as a tumor's size and location. Doctors could better identify and classify cancer cells if technology allowed them to evaluate subtle molecular and chemical changes in different cells. This capability would lead to effective individualized therapies.

A research team led by cell biologist Kristen Kulp and physicist Kuang Jen $\mathrm{Wu}$ is developing techniques using time-of-flight secondary-ion mass spectrometry (ToF-SIMS) to image and classify individual cells on the basis of their mass spectra. The project, which is funded by the Laboratory Directed Research and Development (LDRD) Program, the National Cancer Institute, and the UC Office of the President's California Breast Cancer Research Program, includes CMLS scientists Mark Knize, Elena Berman, Susan Fortson, and Ligang $\mathrm{Wu}$ and biostatistician David Nelson of the Computation Directorate. ToF-SIMS imaging could potentially identify structural variations and functional changes in cells and provide molecular information about the genesis of cancer. This information would allow scientists to develop disease prevention strategies, detection techniques, prognosis predictors, and therapeutic strategies.

The ToF-SIMS research team is focusing on breast, prostate, and bladder cancer, but the techniques could be applied to any type of cancer. In ToF-SIMS, a beam of ions (called the primary ions) desorbs a cloud of secondary ions from

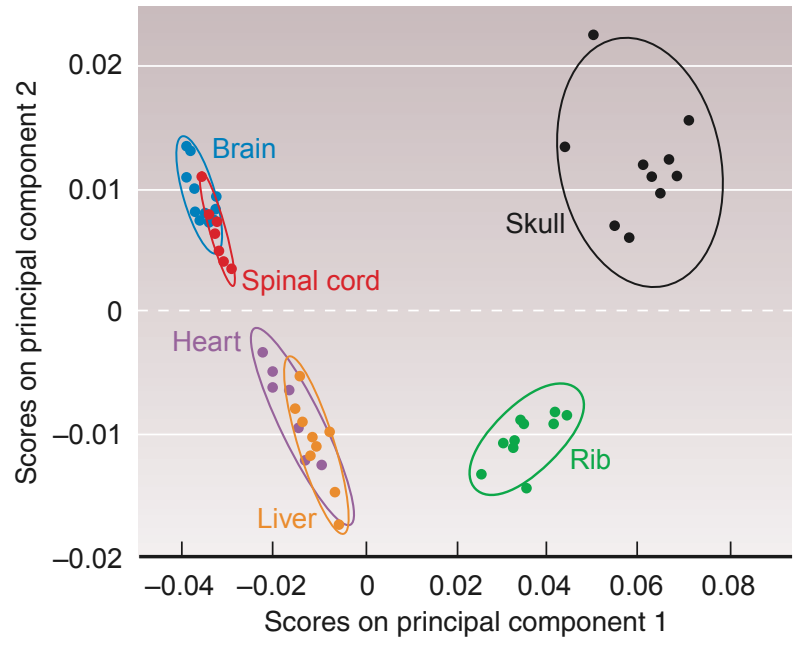

Principal component analysis is a statistical method that highlights the similarities and differences among tissue samples. A principal component is a linear combination of the original variables between samples. Combinations are chosen to show the maximum variation in the samples. a sample's surface and accelerates them toward a time-of-flight detector. The time required for the ions to reach the detector depends on their mass-to-charge ratio (heavier particles are slower). Positionspecific mass spectra are generated by rastering the primary ion beam over the surface of the entire sample.

"ToF-SIMS has been used for 10 to 15 years to produce chemical maps of the surface of inorganic materials," says Kulp, "but little has been done to develop the technique to analyze biological samples. We're developing methods to maximize the information we can get from cancer cells and tissues." The success of the team depends a lot on the expertise of physicist Kuang Jen $\mathrm{Wu}$, who before coming to Livermore, helped design the ToF-SIMS instrument at the company that developed it.

Each ToF-SIMS image contains more than 65,000 individual spectra that represent a sample's chemical makeup. However, most of a cell's mass is composed of proteins, which are made of 20 fairly homogenously distributed amino acids. The ToF-SIMS spectra thus show few unique peaks among different biological samples. To make sense of the complicated data sets and to use the wealth of information being generated, the team applies multivariate statistical analysis techniques that identify differences among the samples and classify the cells.

One data-reduction technique, called principal component analysis (PCA), distinguishes similarities and differences in the ToF-SIMS spectra and can display the complex data as groups on a simple plot. PCA searches for the greatest variation in the data set and plots the data in a way that displays this variation. For example, PCA-derived spectra for a tissue sample from a skull are consistent, but they differ from the spectra for tissue samples taken from another part of the body. Further analysis shows that the skull spectra contain a high concentration of calcium not seen in the soft tissues.

\section{Distinguishing Cancer Cells}

To demonstrate that the combined techniques can image and identify individual cells, the ToF-SIMS team conducted experiments on three breast cancer cell lines: MCF-7, T47D, and MDA-MB-231. These three well-modeled cancers differ in their ability to cause tumor metastasis. When cell populations were homogenized and separated into nuclear, cytoplasmic, and membrane fractions, the team found that the cellular compartments differed for each line. Experiments on individual cells confirmed these differences. The results illustrate 
the potential of ToF-SIMS to detect a single aberrant cell within a normal cell population and to characterize rare chemical changes that may provide clues to single cell progression within carcinogenic and metastatic pathways.

The team is applying the techniques to study bladder and prostate cancers. In the U.S., bladder cancer is the fourth most common cancer type among males and the twelfth most common type among females. Prostate cancer is the second most common cancer-related cause of death in males. For this research, UC Davis pathologist Regina GandourEdwards provides bladder cancer tissue sections taken from patients who have consented to participate in the study. She also identifies the areas of cancer epithelium and supporting tissue that are important to image. David Seligson, a pathologist at the University of California at Los Angeles School of Medicine, provides the team with prostate tissue sections, also collected from consenting patients. At Livermore, Kulp's team correlates ToF-SIMS images of these samples with the information obtained by the pathologists when they analyzed stained tissue slides of the samples.

Preliminary results demonstrate the chemical specificity and sensitivity of ToF-SIMS and PCA. "The tissue sections provide enough chemical information for ToF-SIMS to differentiate cancer cells from normal cells," says Kulp. "The data also indicate that this technique has the potential for defining statistical signatures of bladder and prostate cancer phenotypes." She adds that the team wants to further develop the ToF-SIMS technique so it can help determine a patient's prognosis. "Some tumors develop and remain in the body without causing a problem, while others are aggressive. Today, clinicians can't differentiate the two types. Our techniques may help them prescribe the right therapeutics for the particular type of cancer."

\section{Individualized Cancer Therapy}

A common cancer treatment is chemotherapy. Two effective chemotherapy drugs, cisplatin and carboplatin, contain one platinum atom in each molecule. These drugs slow or halt the growth of cancer cells and interfere with the cells' repair mechanism, thereby leading to cell death. Like many drugs, cisplatin and carboplatin eventually stop working - the cancer cells develop a resistance to the drugs, allowing the disease to progress. The drugs also have toxic side effects. For example, they destroy normal body cells and damage the kidneys and bone marrow.

Another problem is that oncologists typically prescribe chemotherapy based on a patient's weight, age, gender, and liver function. However, individuals with the same age, weight, and physical condition may respond differently to the treatment. Researchers have not previously had a means to study the complex mechanisms involved as drugs interact with different body chemistries.

Livermore's LDRD Program and the National Institutes of Health are funding an AMS project to study how carboplatin interacts with bladder cancer cells. For this project, chemical biologists Paul Henderson and Sang Soo Hah of CMLS and physicists Ted Ognibene and Bruce Buchholz from the Energy and Environment Directorate are working with deVere White and scientist Chong Xian Pan, who specializes in clinical cancer studies at UC Davis. Says Henderson, "Platinum drugs kill cancer cells by damaging the cells' DNA so much that cellular enzymes cannot repair the damage. Some patients respond very well to platinum-based drugs, but others don't because of the individual variation in DNA repair." The team's goal is to develop a technique that identifies chemoresistance
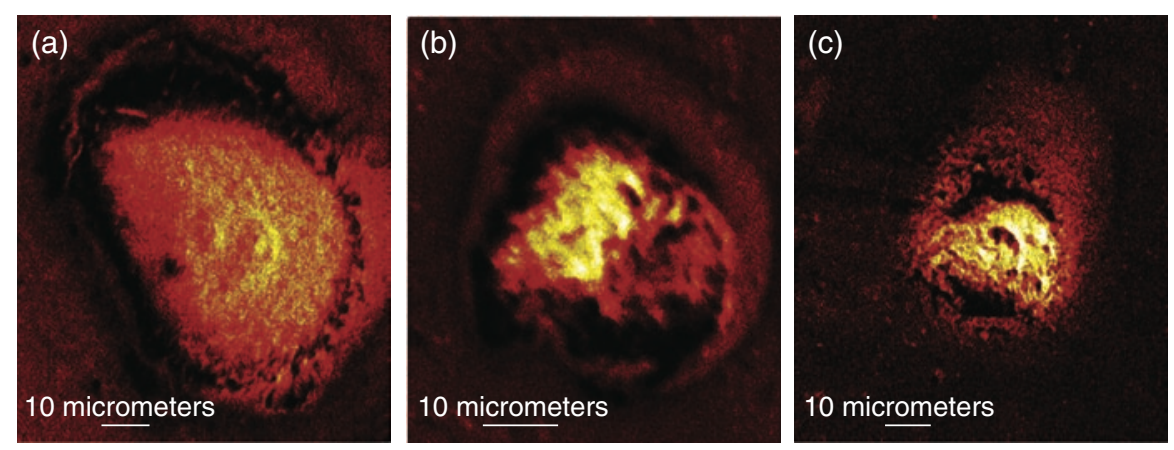

Micrographs show the differences in three breast cancer cell lines: (a) MCF-7, (b) MDAMB-231, and (c) T47D. (d) Principal component analysis of the spectra produced by a time-of-flight secondary-ion mass spectrometer can accurately distinguish the same cell lines.

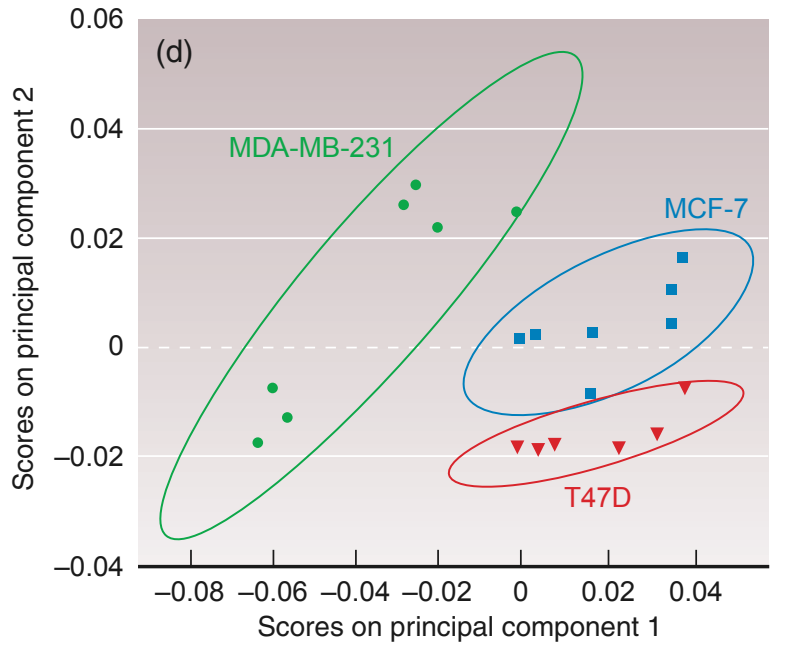


so oncologists can customize a patient's treatment.

Researchers know that anticancer drugs bind to DNA to form adducts (or addition products), but they are not certain which DNA-drug adducts result from the biological activity of platinum-based drugs. With AMS, the team can not only determine the binding kinetics of carboplatin to genomic DNA but also monitor the compound's uptake and nuclear DNA binding in human bladder cancer cells.

AMS is 1,000 times more sensitive than instruments used for conventional assays to characterize DNA damage. It detects changes at the molecular level, such as DNA repair or a protein binding to DNA adducts, and provides a picture of the metabolism of a carcinogen. Conventional assays cannot characterize molecular-level processes or show how they change over time. Carboplatin interacts with the body very quickly. If a patient is responding to the drug, AMS would show a large number of DNA-drug adducts forming. If a patient does not respond to treatment, cells would more rapidly repair their DNA, resulting in fewer DNA-drug adducts.

To measure the kinetics of carboplatin binding to the DNA of bladder cancer cells, the team incubated salmon sperm DNA with a solution of carbon-14-labeled

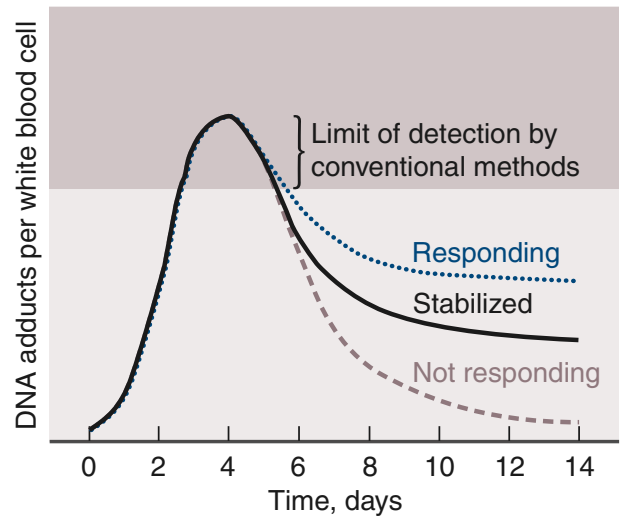

This graph shows the predicted number of DNA-drug adducts after the anti-cancer drug carboplatin is administered. A higher number of DNA-drug adducts indicates a patient is responding to the drug, whereas a lower number indicates the patient is not responding.

carboplatin. (Cisplatin cannot easily be measured by AMS because it does not contain carbon.) The team converted the samples to graphite for AMS analysis and measured the ratio of carbon-14 atoms to total carbon to determine the amount of drug present.

The team will begin human trials in 2007 and plans to conduct clinical studies for other types of cancers. In 2004, the Food and Drug Administration approved carboplatin for the treatment of breast cancer, so the team is developing a project plan for an AMS study of breast cancer cells. "We expect to have a proven protocol for measuring drug pharmacokinetics and DNA damage and repair so we can test platinum-based therapies in individual patients," says Henderson. "AMS technology could also be used to measure drug interactions for many other health problems, such as Parkinson's disease and diabetes."

\section{Targeting Only Cancer Cells}

Disabling the DNA in cancer cells is also the principle behind radiation therapy. Through the ionization process, charged particles damage the molecules, especially the DNA, within cells. Radiation affects both normal and cancerous cells. The cancer cells are less able to repair molecular injury, but the normal cells will die if damage from the radiation is too extensive. Administering the correct dose at the correct spot can be an effective radiation treatment.

Many types of cancers have been successfully treated with gamma-ray systems. However, gamma rays cannot be directed at tumors near delicate structures such as the optic nerve or the retina. Also, gamma rays deposit their energy
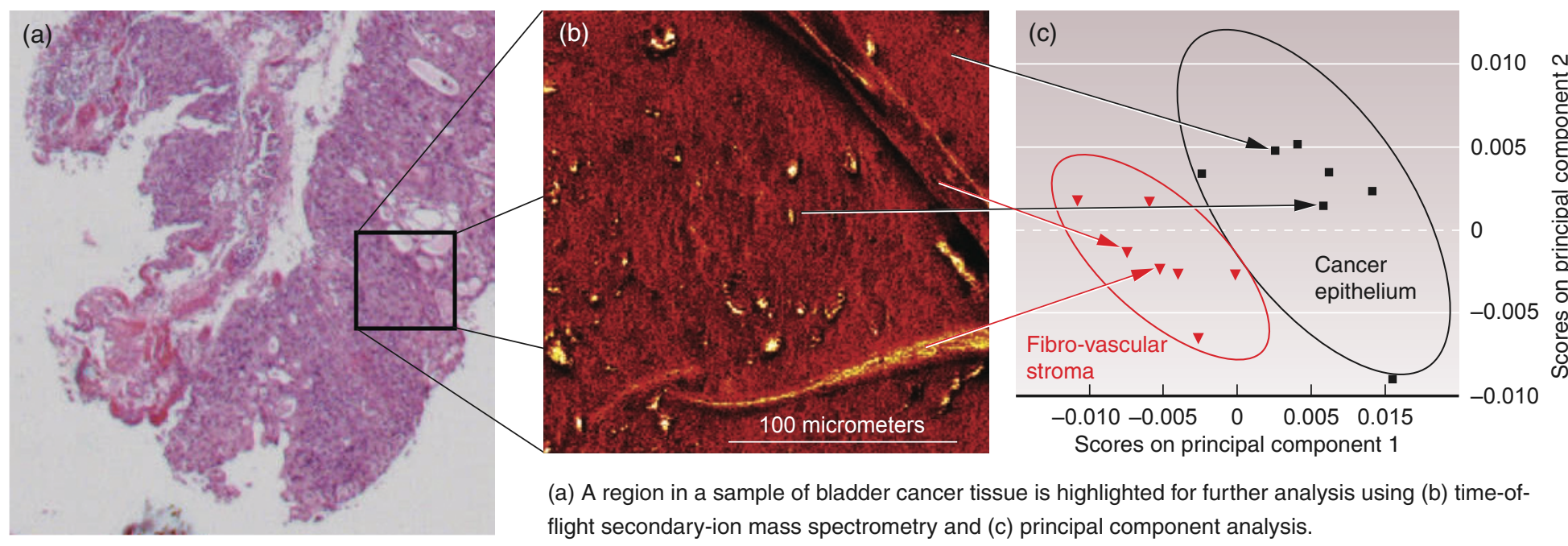

(a) A region in a sample of bladder cancer tissue is highlighted for further analysis using (b) time-offlight secondary-ion mass spectrometry and (c) principal component analysis. 
uniformly, beginning near the body's surface and continuing well beyond the cancer site to damage healthy tissues.

In 1946, physicist Robert Wilson, then at Lawrence Berkeley National Laboratory, proposed using protons for radiotherapy. Two years later, experiments at Lawrence Berkeley confirmed the benefit of this approach. Protons deliver most of their energy at a specific depth in the tissue, which is determined by the protons' energy. Low-energy protons travel a short distance and deliver their energy, while higher-energy protons travel farther before releasing theirs. A proton beam can thus be calibrated to target specific areas of the body. Its precision can be so exact that healthy tissue a few millimeters from the target area receives almost no radiation.

Proton beam therapy has been available since 1990, but few organizations have the resources to build and operate the required facilities. In the past, large particle accelerators such as cyclotrons or synchrotrons were required to produce high-energy proton beams. These instruments occupy as much space as a basketball court, and construction alone costs up to $\$ 200$ million. Concrete walls also must be built to protect people outside the treatment room from the radiation generated. The U.S. has only a few of the 20 or so facilities available worldwide. The development of a compact proton accelerator could dramatically reduce the cost of building proton therapy centers.

\section{Choosing the Best Materials}

In 2003, the LDRD Program funded a project to explore the concept of a compact proton accelerator called a dielectric wall accelerator. The project team, led by physicist George Caporaso of Livermore's Physics and Advanced Technologies Directorate, originally focused on defense-related applications until Dennis Matthews proposed designing a version for cancer therapy. Caporaso says, "The principle behind the compact system is an accelerator tube composed of sections, or rings, each with transmission lines. A series of switches sequentially apply voltage to the transmission lines, and the high electric field propels the particles through the vacuum. The timing of the switches controls the accelerator wave so that its speed matches the particle's speed."

The accelerator uses an insulating pipe, or dielectric wall, to maintain a vacuum while preventing the accelerator from short-circuiting. A common problem with insulators is a phenomenon called

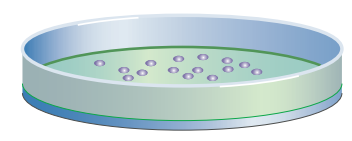

Plate with cells
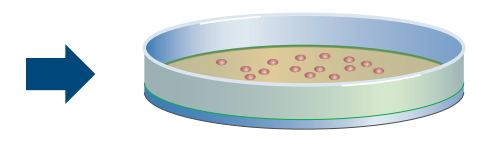

Cells grown in media spiked with carbon-14-labeled carboplatin
A sample from bladder cancer cells is incubated with a solution of carbon-14-labeled carboplatin to measure the kinetics of carboplatin binding to the DNA. Cells are then isolated from the solid sample and an accelerator mass spectrometer (AMS) measures the ratio of carbon-14 atoms to total carbon to determine the amount of drug present. $\mathrm{COOH}=$ carboxylic group compound, $\mathrm{H}_{2} \mathrm{~N}$ and $\mathrm{NH}_{2}=$ amino group compounds, $\mathrm{O}=$ oxygen, and $\mathrm{Pt}=$ platinum.
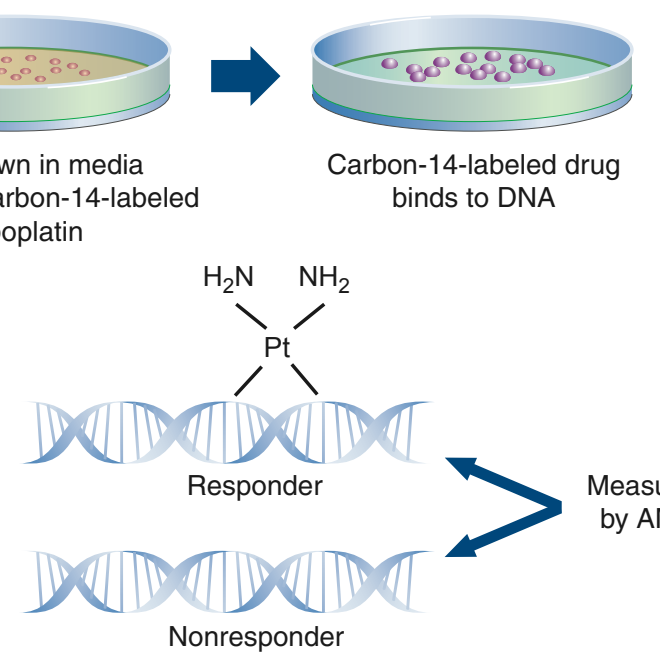
binds to DNA surface flashover. During high-voltage conditions, the electrodes that accelerate the charged particles produce unwanted electrons that gain energy from the strong electric field. These electrons then collide with the insulator's surface, which liberates additional electrons and gas molecules adsorbed on the insulator. This process continues, eventually resulting in a gas buildup that sparks.

In the 1980s, researchers found they could design accelerators to withstand a higher electric field by imbedding thin metal layers within the insulator. They hypothesized that the metal layers interrupt the surface flashover process by deflecting or capturing the unwanted electrons before they can collide with the insulator surface. In Livermore's dielectric insulator, conducting layers made of a metal such as stainless steel alternate with insulating layers of a plastic, such as polystyrene. The technology won an R\&D 100 Award in 1997. (See $S \& T R$, October 1997, pp. 16-17.)

John Harris, an engineer in Livermore's Accelerator Design and Code Group, is conducting experiments to determine requirements for the high-gradient insulators to be used in a dielectric wall accelerator for proton therapy. In the Livermore design, insulator rings are
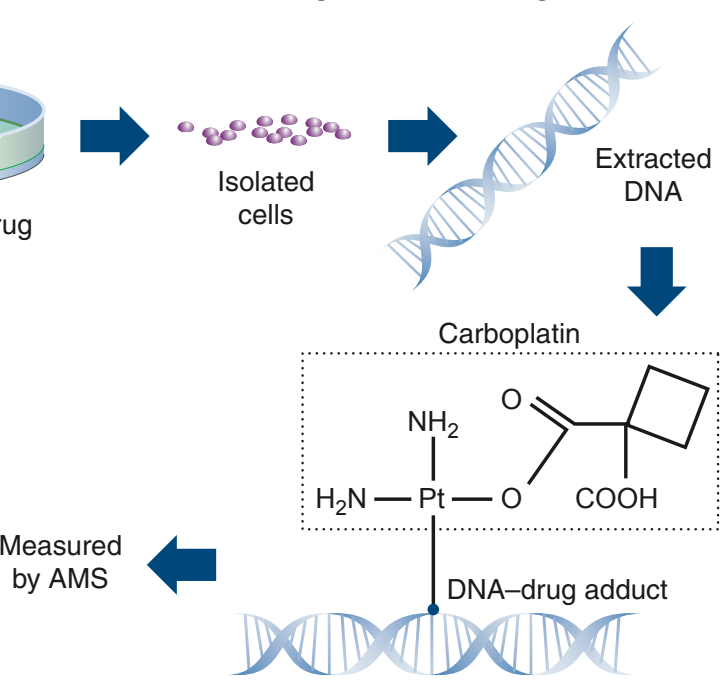
(a)

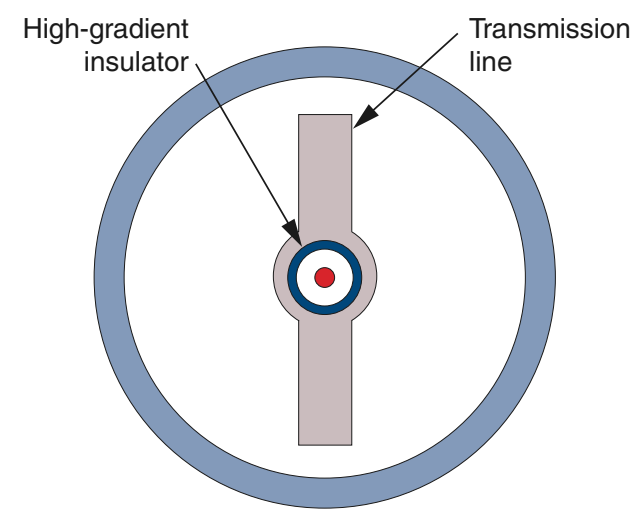

(b)

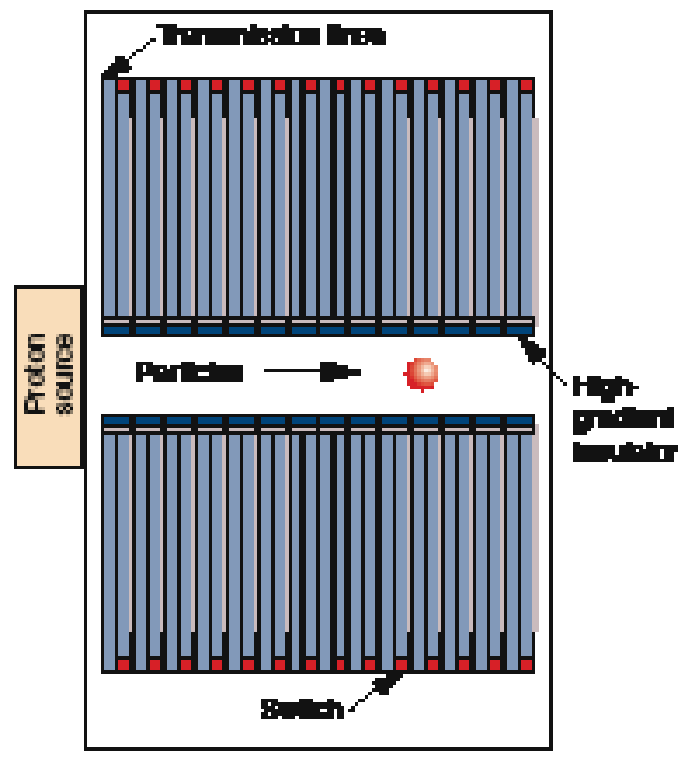

(c)

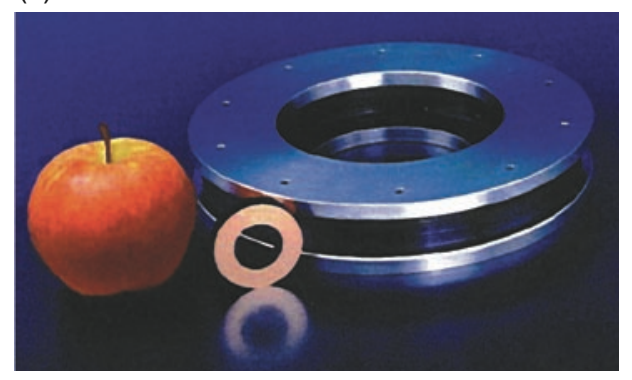

A compact dielectric wall accelerator is composed of a stack of rings made from thin, alternating layers of a metal and an insulator: (a) side view, (b) top view, and (c) sample ring. Transmission lines embedded in the rings produce the electric fields that propel charged particles along the tube. As the particles travel, a series of switches open and close, controlling the voltage applied to transmission lines in each section.

capabilities of both institutions. Says Kulp, "We're making advances in our studies on cancer cells because we can pull together a multidisciplinary team that includes a chemist, a biologist, a pathologist, a physicist, and a statistician." Together, researchers have pioneered many technologies to help in the fight against cancer.

"When we formed the integrated cancer program in 2000 , we laid out an exciting vision of what the collaboration might bring," says deVere White. "I doubt any of us could have imagined the success it already has become or the potential for good that it holds for the future."

- Gabriele Rennie

Key Words: accelerator mass spectrometry (AMS), cancer, carboplatin, cisplatin, dielectric wall accelerator, principal component analysis (PCA), proton accelerator, proton beam therapy, time-of-flight secondary-ion mass spectrometry (ToF-SIMS), University of California (UC) Davis Cancer Center.

For further information contact Jim Felton (925) 422-5656 (felton1@IInl.gov). 


\section{Computational tools}

\section{developed at the National}

\section{Atmospheric Release}

\section{Advisory Center predict}

\section{the spread of airborne}

\section{hazards from toxic}

chemical spills, fires,

\section{and other atmospheric}

\section{releases.}

On March 29, 1979, Llvermore scientists responded to the Three Mile Island nuclear power plant accident, using the Laboratory's computational tools to predict the dispersion of radioactive fallout. Soon after this incident, the Department of Energy established the National Atmospheric Release Advisory Center at Livermore to better protect the nation from airborne hazards.
ENSORS detect an airborne hazardous material, and authorities quickly contact the National Atmospheric Release Advisory Center (NARAC) at Lawrence Livermore. Within 15 minutes, NARAC's suite of Web-based software produces fully automated, three-dimensional (3D) predictions that show which areas will be exposed to toxic levels of the airborne plume and provide protective action guidelines for emergency responders. The center's operations staff, which is on duty or on call around the clock, follows up with refined models calibrated with field measurements of airborne and surface concentrations of the toxic material.

Newly acquired data are included in computer simulations to better predict the plume's direction and its likely source. The revised projections give emergency responders and decision makers valuable information about hazard areas, potential health effects, populations at risk, and recommended protective actions. This hypothetical incident illustrates the services that NARAC provides dozens of times each year.

A toxic airborne release, whether intentional or accidental, can quickly affect a large population. To better protect the nation from such hazards, the Department of Energy (DOE) established NARAC in 1979 in the wake of the Three Mile Island nuclear power plant accident. The center's purpose is to respond to such events by predicting and mapping the probable spread of hazardous materials released into the atmosphere. Livermore scientists provide support during emergencies involving many kinds of potential atmospheric hazards - toxic industrial chemical spills, fires, biological and chemical agent releases, radiological dispersal devices, improvised nuclear weapons, and nuclear power plant accidents.

In 2004, the Homeland Security Council named NARAC as the interim provider of capabilities for the new Interagency Modeling and Atmospheric Assessment
Center (IMAAC), which is led by the Department of Homeland Security (DHS). Under the U.S. National Response Plan, IMAAC coordinates dispersion modeling and disseminates hazard predictions for actual or potential incidents that require federal coordination.

NARAC receives real-time observations and weather forecast data feeds from the National Weather Service's National Centers for Environmental Prediction, the U.S. Navy and Air Force, and many other sources around the world. The center collects more than one million meteorological observations per day. By combining this information with the center's databases of maps, terrain, land use, population, material properties, and release mechanisms, the operations staff can use NARAC computer models to generate predictions that focus on almost any area, whether the scale is urban, regional, or global.

To provide integrated emergency response support, NARAC collaborates with more than 300 federal, state, and local agencies and emergency operations centers. The center's operational system responds to about 7,000 requests per year and has over 1,800 online users. An easy-to-use geographic information system (GIS) displays plume predictions and can export results to other GIS tools. Predictions can be requested and distributed with user-friendly Internetand Web-based software, and access is available via dial-up, satellite, Ethernet, and wireless networks.

\section{Staying on the Leading Edge}

Gayle Sugiyama, who leads the NARAC/IMAAC Program in Livermore's Energy and Environment Directorate, ensures that models and codes are continually updated to incorporate the latest computational and scientific capabilities. "NARAC's operational needs drive our research and development, which in turn directly benefit the operations team and its clients," she says. 
Currently, one-third of the center's staff is devoted to model and system research. Other staff members analyze airborne hazards or maintain the hardware and software systems. NARAC scientists routinely collaborate with other Laboratory engineers and scientists and with researchers at various institutions.

The center's current projects encompass a variety of prediction capabilities. New research areas include simulating releases in complex urban environments and developing probabilistic methods that use field measurements to reconstruct atmospheric release events and determine an unknown source. In other projects, scientists are incorporating new capabilities into existing dispersion models, including the effects of high-altitude releases, rain, atmospheric chemistry, and surface roughness. The center is also making significant improvements in its models of nuclear fallout, dense gases, and the resuspension of particles.

\section{Simulating the Urban Scene}

Cities represent a challenge for airborne flow and dispersion modeling. Buildings, sidewalks, and streets capture heat, creating urban heat islands. Structures and vegetation complicate the flow patterns, for example, channeling dispersion down the street canyons formed by high-rise buildings and causing wake zones and eddies to form. All of these surface features significantly affect the movement of an airborne plume. An indoor exposure to material released outdoors differs significantly from an outdoor exposure. Buildings "leak," and ventilation systems move contamination in or out of buildings. People and traffic carry contaminants with them, increasing the size of the hazard area.

NARAC has long been a leader in developing urban modeling techniques. As computing power increases, scientists have improved the center's atmospheric flow and dispersion models to encompass higher spatial and temporal resolutions as well as more complex physical processes. This computational capability is particularly important for national security because cities are potential targets for weapons of mass destruction.

To better predict dispersion in an urban environment, NARAC scientists have developed a computational fluid dynamics (CFD) code called FEM3MP. (See S\&TR, October 2001, pp. 16-19.) FEM3MP is a massively parallel code that generates accurate predictions of wind fields and dispersed concentrations. The code has been extensively tested against data obtained from wind-tunnel and field experiments, such as Urban 2000 in Salt Lake City, Utah, and Joint Urban 2003 in Oklahoma City. Livermore physicist Stevens Chan is responsible for ongoing development of FEM3MP.

FEM3MP is an excellent tool for the detailed site studies so crucial for emergency response planning and postevent analysis. It is, however, computationally intensive and is too slow for real-time predictions. A major roadblock to using FEM3MP and similar CFD codes in an emergency situation is the time required to generate the grids used in calculations.

To address this problem, scientists from NARAC and Livermore's Computation Directorate are incorporating FEM3MP's capabilities into the Adaptive Urban Dispersion Model (AUDIM). AUDIM uses adaptive mesh refinement to automate and integrate the steps in simulating dispersion in an urban environment, from grid generation to flow and transport prediction. AUDIM's grid-generation program can use raw lidar data from aerial surveys as well as "shape files" of building footprints and heights to generate 3D surface meshes in minutes.

A faster method for simulating an urban airborne dispersal is the Urban Dispersion Model (UDM), developed by the United Kingdom's Ministry of Defence

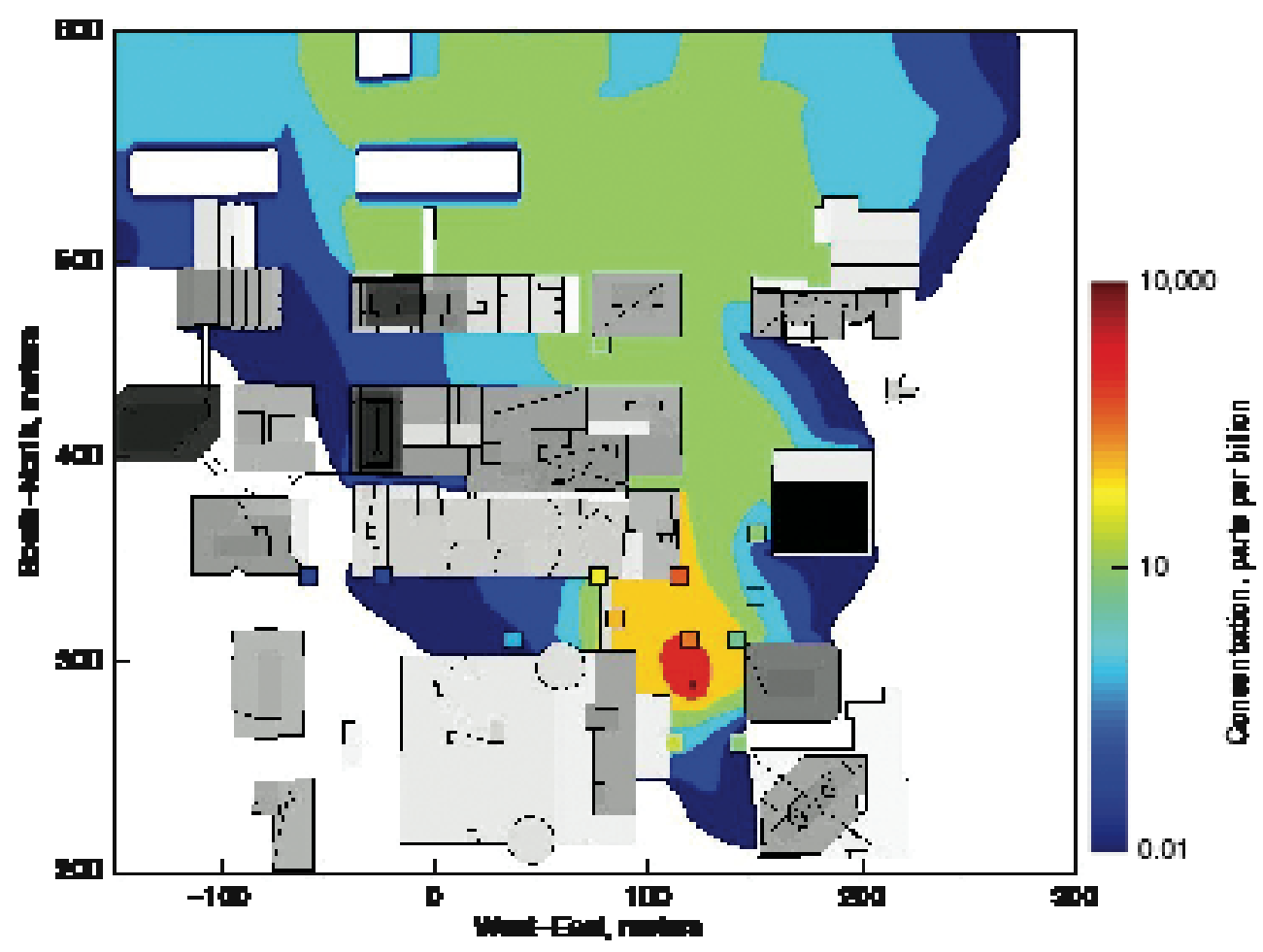

These concentration predictions, which were made by the computational fluid dynamics code FEM3MP, compared well with data collected during the Joint Urban 2003 field experiment. 
at the Defence Science and Technology Laboratory. UDM fills a gap between highly detailed CFD simulations and larger-scale urban canopy models, which use areaaveraged data that do not resolve individual buildings. UDM empirically incorporates the effects of buildings on airborne transport. A joint project with the Defence Science and Technology Laboratory has completed a pilot integration of UDM into the NARAC operational system.

In another effort, Livermore physicists Lee Glascoe and Gwen Loosmore are working with computer scientist Hoyt Walker to address indoor exposure from an outdoor release. Their effort is based on building infiltration (leakiness) models developed by Lawrence Berkeley National Laboratory. "Building leakiness affects the dose to which an indoor population may be exposed during an airborne release," says Glascoe. "Understanding building infiltration leads to better decisions about evacuation versus sheltering in place."

Leakiness varies with the type of structure as well as with local weather conditions. For example, houses in California leak more than houses in colder Minnesota. Homes in economically disadvantaged communities also tend to have higher leakiness factors. With

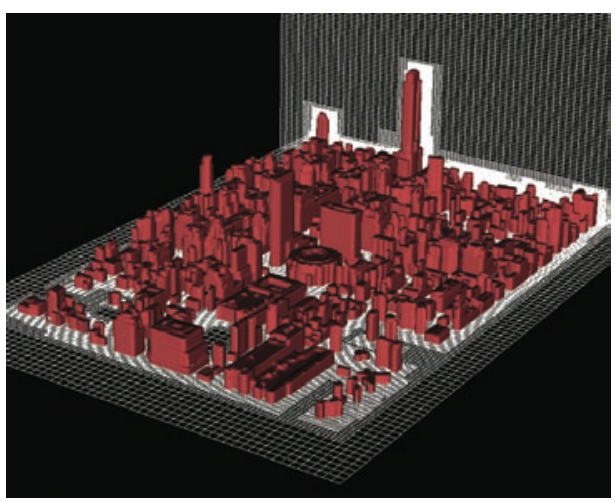

The Adaptive Urban Dispersion Model (AUDIM) automatically produces large, high-resolution computational grids for complex urban environments. AUDIM created this detailed grid of lower Manhattan in less than 10 minutes.

(a)

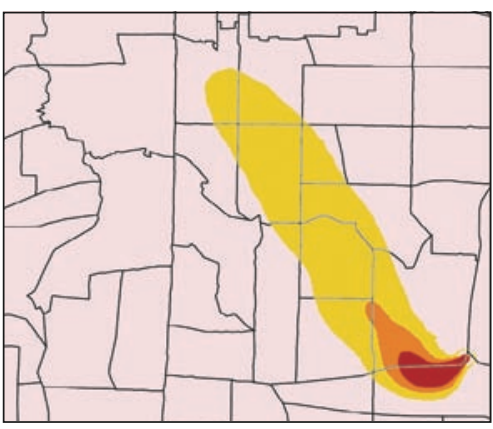

(b)

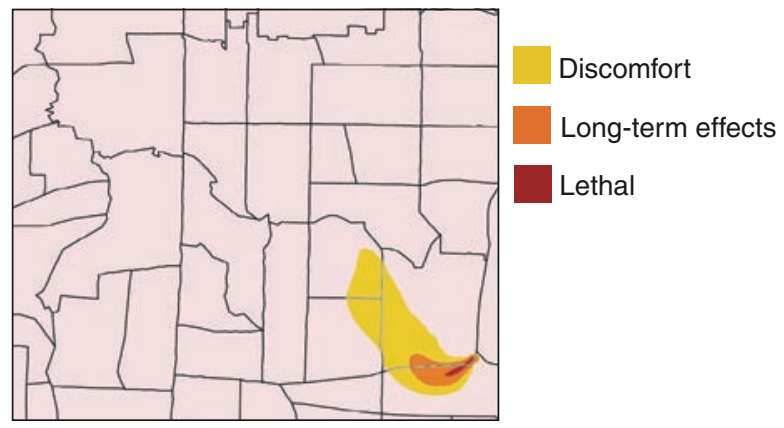

(a) Modeling results show that the atmospheric release of a toxic agent would affect several counties in a region, as winds carried the materials northwest. (b) People who remained sheltered inside buildings would be better protected from the release.

\section{Evaluating Model Performance}

Scientists at the National Atmospheric Release Advisory Center (NARAC) test new simulation techniques and operational systems extensively to ensure that all of the center's tools perform as designed. Comparing predictions with analytic solutions is one method of testing models to measure how well new tools perform. Real events, such as the 2004 chemical fires in Cincinnati, Ohio, and Conyers, Georgia, make excellent operational test cases.

Another test method is field experiments. Livermore has participated in several field studies, including Urban 2000 in Salt Lake City, Utah, and Joint Urban 2003 in Oklahoma City. These experiments were collaborations of Department of Energy (DOE) national laboratories, other federal agencies, and universities to collect field data for testing urban flow and dispersion models. Urban 2000, funded by DOE, studied nocturnal releases under relatively light wind conditions. Joint Urban 2003 was the largest and most complex urban field experiment performed to date. Funded by the Department of Homeland Security and the Defense Threat Reduction Agency, this experiment consisted of daytime and nighttime releases of sulfur hexafluoride under moderate to strong winds.

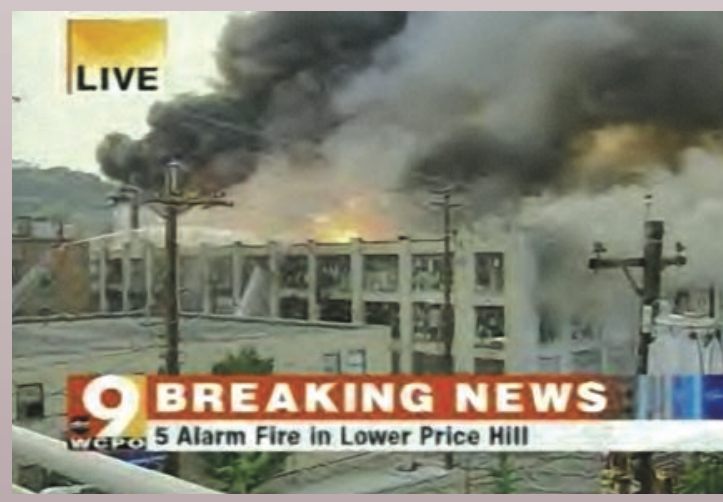

NARAC provided operational support for officials in Ohio during a massive fire at an illegal chemical storage facility. (Photograph courtesy of WCPO-TV, Cincinnati, Ohio.)
Results from such experiments help researchers improve their modeling efforts. For example, observations at Joint Urban 2003 influenced NARAC's work on urban atmospheric turbulence for the Weather Research and Forecasting model. Conventional approximations of turbulence cannot account for the concentrations of sulfur hexafluoride measured during the exercise. Incorporating turbulence more accurately in forecasting models could make all the difference. 
commercial buildings, leakiness depends on a structure's footprint, height, and geographic location. To improve simulations of indoor exposures, the Livermore team used census tract data to develop estimates of residential leakiness throughout the U.S. The team, which includes researchers from Lawrence Berkeley, recently completed a prototype code that can predict exposures to an outdoor chemical gas release for occupants of a commercial building. The team is working on a similar code to model aerosol release exposures.

Physicist Julie Lundquist is working with scientists from the University of California at Berkeley to incorporate the effects of the urban landscape - factors such as turbulence and heating - in the next-generation weather forecasting program, known as the Weather Research and Forecasting (WRF) model. WRF, which is being developed by the National Center for Atmospheric Research and many other institutions, will be a valuable resource both for weather forecasting and scientific research. Livermore is modifying WRF for use in detailed, urban dispersal simulations. (See the box on p. 15.)

\section{Reconstructing a Release}

During many events, the greatest unknown factor is the source term: the data that define the physical and chemical properties of the airborne material, the quantity released, and the event's time and location. Fast answers about the source term can speed up emergency response, consequence management, and restoration activities. "The future for NARAC is improving the way we deal with unknown sources," says Livermore physicist Branko Kosovic.

Kosovic leads a team of NARAC researchers who are developing an event reconstruction methodology to estimate source terms and assess their likely impacts. Current methods for determining sources rely on first responders or analysts to estimate source characteristics, which are used as input to predictive models. (See the box on p. 17.) Because the variety and quantity of data available continue to increase during an airborne release, a high priority at NARAC is to develop a rigorous event reconstruction methodology that can take full advantage of incoming data.

The atmosphere is by nature chaotic. Sophisticated statistical sampling processes are required to model its unpredictable, nonlinear nature. Kosovic's team is developing an atmospheric event reconstruction framework based on a stochastic engine originally developed at Livermore to predict the behavior of subsurface contaminant plumes. (See S\&TR, July/August 2002, pp. 21-23.) This methodology combines field measurements and model predictions via Bayesian

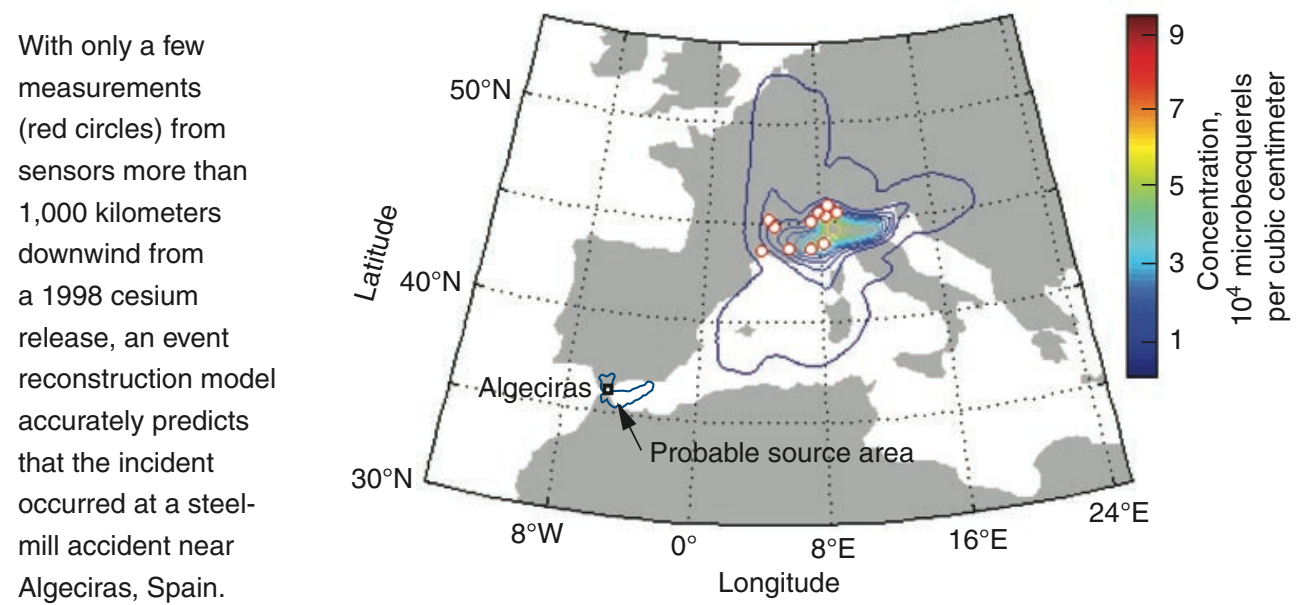

inferencing and stochastic sampling to produce probabilistic estimates of unknown parameters. The development project was funded by the Laboratory Directed Research and Development (LDRD) Program and incorporated expertise from four Laboratory directorates.

This event reconstruction framework allows the use of multiple stochastic sampling algorithms and predictive models. In tests of the methodology, former postdoctoral researcher Tina Chow used FEM3MP and data collected during the Joint Urban 2003 field experiment in Oklahoma City to accurately reconstruct the source term and contaminant plume. With no prior information about the source location, the probabilistic computer calculations - called Markov chains - quickly focused on a half-block region containing the actual source location, as shown in the figure on p. 17, while simultaneously determining the approximate release amount. These results have been used to construct a "composite" plume showing the 90 -percent probability level that concentrations exceed a given amount. Graduate student Stephanie Neumann and her colleagues performed a similar reconstruction using UDM.

The reconstruction methodology also was applied to an actual event involving a continental-scale release of radioactivity. On May 30, 1998, a piece of medical equipment containing cesium137 was accidentally melted in a steel mill near Algeciras, Spain. The incident was first detected on June 1 and 2 by sensors in France and Italy. On June 9, the Swiss government announced that its national monitoring network had detected radiation levels up to 1,000 times background values. Because winds from the west drove the plume over the Mediterranean Sea, no Spanish sensors recorded the increased radioactivity. On June 10, the steel mill finally notified the Spanish Nuclear Security Agency that radiation had been detected in the mill's stack filters. Fortunately, none of the 
radioactivity levels recorded in Europe or near the source were sufficient to adversely affect the health of people or the environment.

In reconstructing this event, Livermore physicist Luca Delle Monache started with a possible accident domain that reached from northern Africa to well north of Scotland, an area extending 1,800 kilometers east to west and 3,600 kilometers north to south. The predicted source locations defined by the NARAC simulation cluster near the actual source. Says Delle Monache, "If these tools had been available in 1998, we could have provided predictions to authorities three days after the accident and helped pinpoint the release."

\section{Upping the Physics Ante}

Several NARAC projects focus on increasing the accuracy of physical models in existing dispersion codes. In a major DOE initiative, NARAC/IMAAC associate program leader John Nasstrom is working with physicists Kevin Foster and Ted Harvey to develop a nuclear fallout model that accounts for the complex patterns of wind flow and terrain. The model

\section{Operational Event Reconstruction}

Gayle Sugiyama, the program leader at the National Atmospheric Release Advisory Center (NARAC), is particularly proud of her team's performance at the most recent Top Officials (TOPOFF) Field Exercise. The TOPOFF3 exercise, held in April 2006 at the New London City Pier in Connecticut, involved more than 10,000 participants representing over 200 federal, state, local, tribal, private sector, and international organizations as well as volunteer groups - all responding to multiple simulated large-scale terrorist attacks.

TOPOFF3 started on April 4 with the simulated explosion of a truck bomb near a large public gathering at the pier. Twenty minutes after the explosion, the Department of Homeland Security's Interagency Modeling and Atmospheric Assessment Center (IMAAC) was asked to analyze the source for the release. Mustard gas was used as a possible release agent, based on intelligence reports that terrorists might be developing chemical agents in the New England area.

As additional information on the size of the bomb arrived, Livermore team members concluded that the explosion was so large, it would have destroyed most of the mustard gas carried by a truck. However, reports from the field cited casualties with symptoms for a blister agent. In looking for other potential sources, analysts found that a low-flying plane had been observed over the pier more than two hours before the truck bomb.

The NARAC team generated a new analysis for IMAAC showing that the amount of material a small plane could carry was consistent with the number of casualties. Just before nightfall, IMAAC received an initial set of deposition measurements, and the NARAC team used these data to predict the plane's flight path and the amount of material released.

"That night and the next day, we were continually given misleading information," says Sugiyama. "Several agencies insisted the truck bomb was the source for the blister agent. But our analysis confirmed that a release from the aircraft was the only plausible source. Our scientists stood by their analysis." On day 3, a full set of field measurements confirmed the team's conclusions and showed that predictions made on day 1 were within 10 percent of the correct quantity.
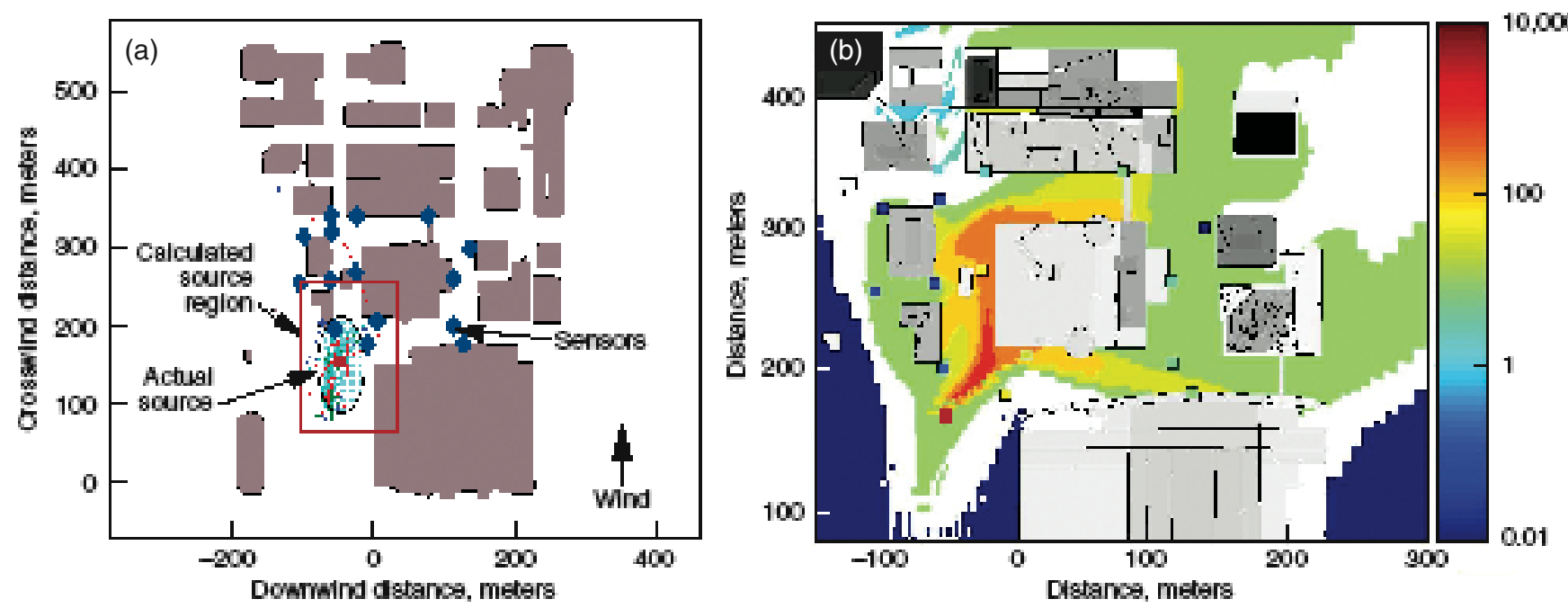

A stochastic algorithm and the computational fluid dynamics code FEM3MP are being used together for event reconstruction. To test the model's accuracy, researchers ran simulations using data from the Joint Urban 2003 exercise in Oklahoma City. The model (a) successfully identified the half-block area (black oval) that included the actual source location (red square) and (b) produced the composite plume showing concentrations with a 90-percent probability of occurrence. 
predicts not only gross radioactivity but also specific nuclides, and it can simulate multiple weapon bursts as well as global transport of radioactive materials.

Another research effort incorporates the effects of rain on an atmospheric dispersion. Raindrops grab dispersed particles and deposit them on the ground, a process called precipitation scavenging. Scavenging creates hot spots of deposition, a phenomenon seen after the Chernobyl accident. NARAC's models now incorporate spatially varying precipitation based on weather forecast data and the intertwining effects of raindrop and particle size. Says Loosmore, "The next step for even greater accuracy will be to use precipitation data directly from a live weather radar feed, when it is available."

Until recently, NARAC's workhorse codes have been limited in their ability to model the interaction of chemical or biological agents with the atmosphere. For example, when the nerve gas sarin meets naturally occurring hydroxyl radicals $(\mathrm{OH})$ in the atmosphere, $\mathrm{OH}$ grabs hydrogen atoms to create water
$\left(\mathrm{H}_{2} \mathrm{O}\right)$ and in the process destroys the sarin. Because the destruction is cumulative, the effect of the chemical reactions increases as the plume ages. The net effect could thus significantly decrease the area at risk. $\mathrm{OH}$ is not an abundant molecule in the atmosphere, but its high reactivity makes it an important component for atmospheric chemistry.

"Chemical changes during a dispersal are important for first responders," says atmospheric chemist Philip CameronSmith. "With more accurate plume predictions that consider atmospheric chemistry, the area to target with an antidote is much smaller."

Another project, which started with LDRD funding, is an effort to model high-altitude dispersion from a warhead carrying a biological or chemical weapon. Now funded by the Defense Threat Reduction Agency, this research is combining high-altitude weather data from the National Aeronautics and Space Administration (NASA) with NARAC's dispersal codes to improve the accuracy of the simulation results. The model also takes into consideration the rarefied physical environment at high altitudes.

\section{Future of NARAC Science}

Several projects just getting started will improve NARAC predictions and the services provided to IMAAC. Lundquist will soon begin working with collaborators at NASA to obtain data from satellites about Earth's surface roughness. The land surface - grassy fields, a dense forest, small or large cities, lakes - significantly affects winds, turbulence, and plume dispersion. With improved roughness data, models can more accurately predict the spread and trajectory of hazardous plumes.

Loosmore is responsible for two new projects that will improve the center's operational codes. One effort involves the resuspension of particles. Biological agents and radioactive particles deposited on a surface may be returned to the atmosphere if, say, a car drives by. Resuspension can further spread contamination, resulting in new opportunities for exposure. The resuspension process is notoriously difficult to model because of the complex (a) An updated model for fallout from nuclear explosions produces more accurate results than (b) the existing operational model.
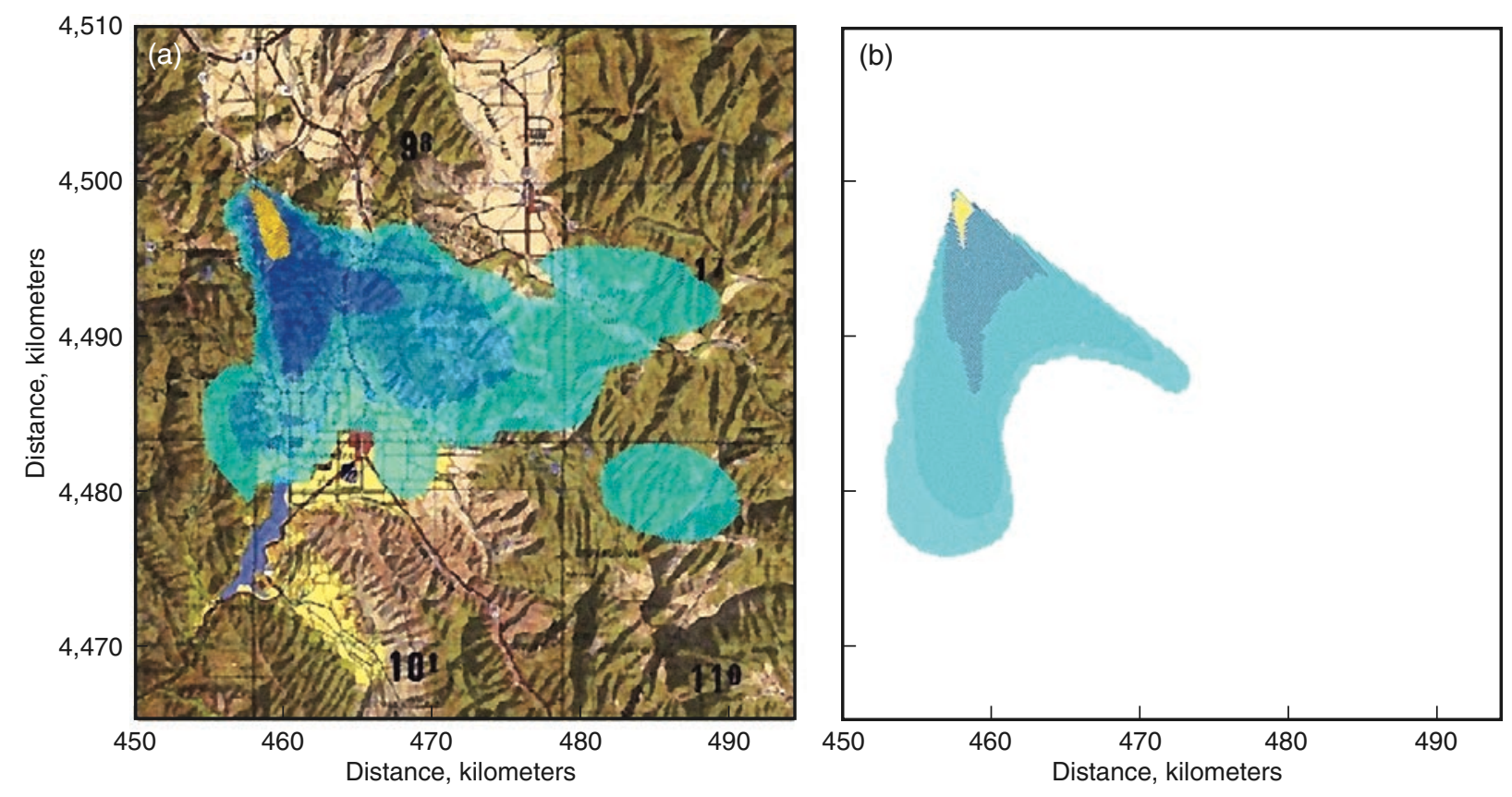

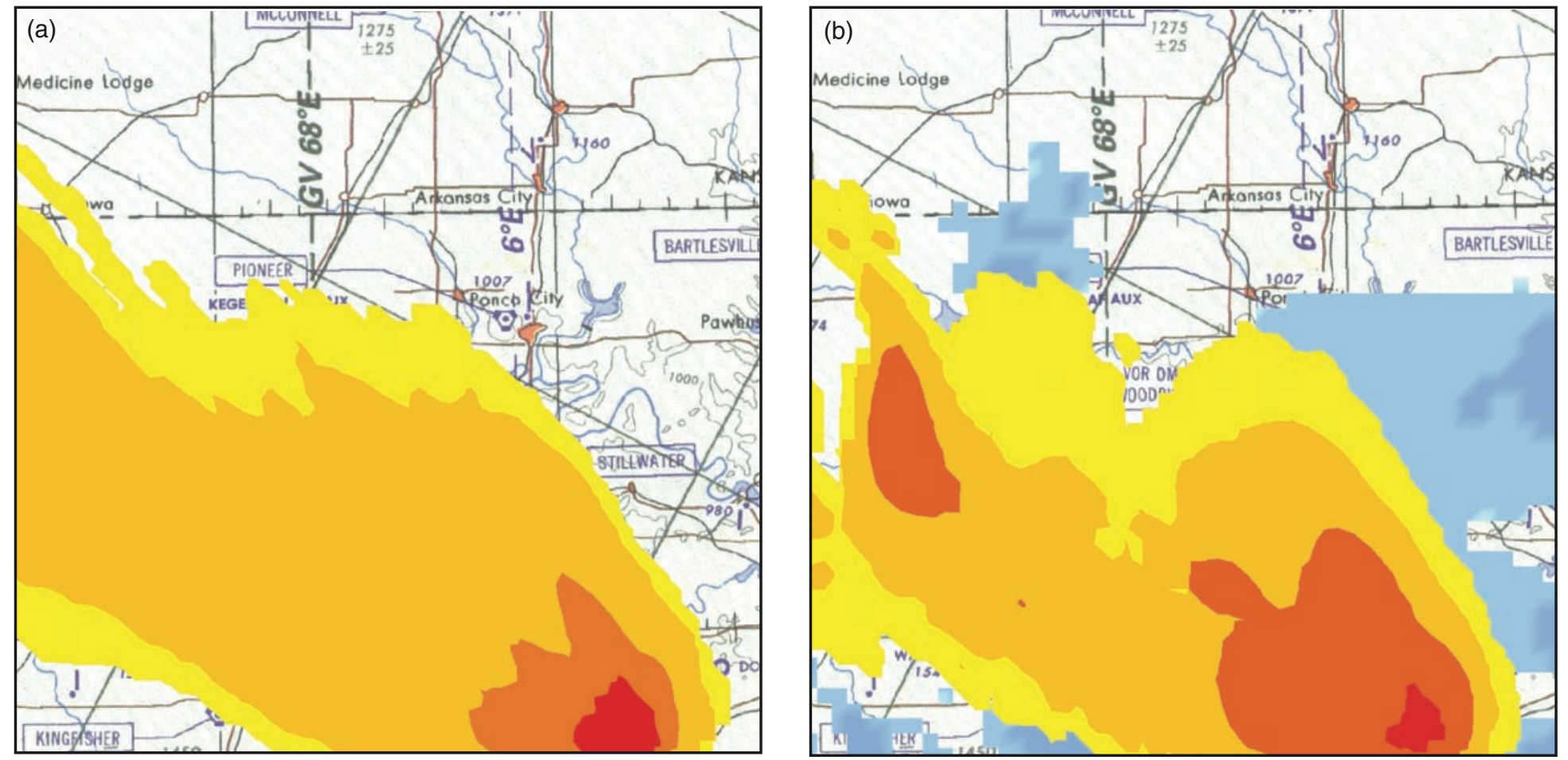

Including precipitation data in dispersion models improves the accuracy of predictions. (a) With constant rainfall at 30 millimeters per hour, the model produces relatively uniform contours of the predicted ground deposition, which ranges from red (highest) to yellow (lowest). (b) When high-resolution precipitation data (blue) are included in the calculation, the model predicts that deposition hot spots will occur in several areas.

turbulence and chemistry that occur where particles meet the atmosphere.

Her second research effort is an LDRD project focused on incorporating the properties of heavier-than-air gases such as chlorine into FEM3MP simulations of dispersions in urban areas. "Dense gases typically reduce turbulence while buildings increase it," says Loosmore. "Our challenge is to determine how these competing effects work together."

A team of researchers is also enhancing FEM3MP to simulate how different material surfaces and sun versus shade affect bioaerosol degradation and viability. For example, particles will be quickly destroyed if they are deposited on a window in direct sunlight. In contrast, particles that stick to stucco in the shade will remain viable longer. To improve the nation's response capabilities, DHS needs models that accurately predict the sampling required to characterize the extent of contamination following a biological attack in complex urban environments. Such a capability would reduce the time and expense of restoration efforts.

NARAC models and the services provided for IMAAC are being incorporated into other operational systems for detection, warning, and incident characterization. In the future, researchers hope to couple operational models with epidemiological models and data on public health and waterborne hazards. As advances in these many projects are made, NARAC can only get better at protecting the public.

-Katie Walter
Key Words: airborne toxic release, atmospheric chemistry, computational fluid dynamics (CFD), event reconstruction, fallout model, FEM3MP, Interagency Modeling and Atmospheric Assessment Center (IMAAC), National Atmospheric Release Advisory Center (NARAC), precipitation scavenging, urbanscale dispersion model, Weather Research and Forecasting (WRF) model.

\section{For further information contact Gayle Sugiyama (925) 422-7266 (sugiyama1@IInl.gov).}




\section{Climate and Agriculture: Change Begets Change}

A.

S any farmer will tell you, the production of food relies greatly on the weather. Historically, weather fluctuated from year to year, while climate - the average weather conditions over time-remained much the same. Now, increases in the atmospheric levels of carbon dioxide and other greenhouse gases have led to an unmistakable climb in the global temperatures during the past 20 years. As a result, scientists, farmers, and government officials are struggling to understand what effects a permanently warmer climate will have on agriculture.

Lawrence Fellow David Lobell is working with colleagues from Livermore, the University of California at Merced, Carnegie Institution, and Stanford University to examine the relationship of global warming and food production. Climate change research at the Laboratory supports the Department of Energy's mission priorities in energy and environment. Lobell's team is modeling the climate-induced changes projected for agricultural regions such as the Central Valley of California and how these changes will affect crop growth. "We're determining

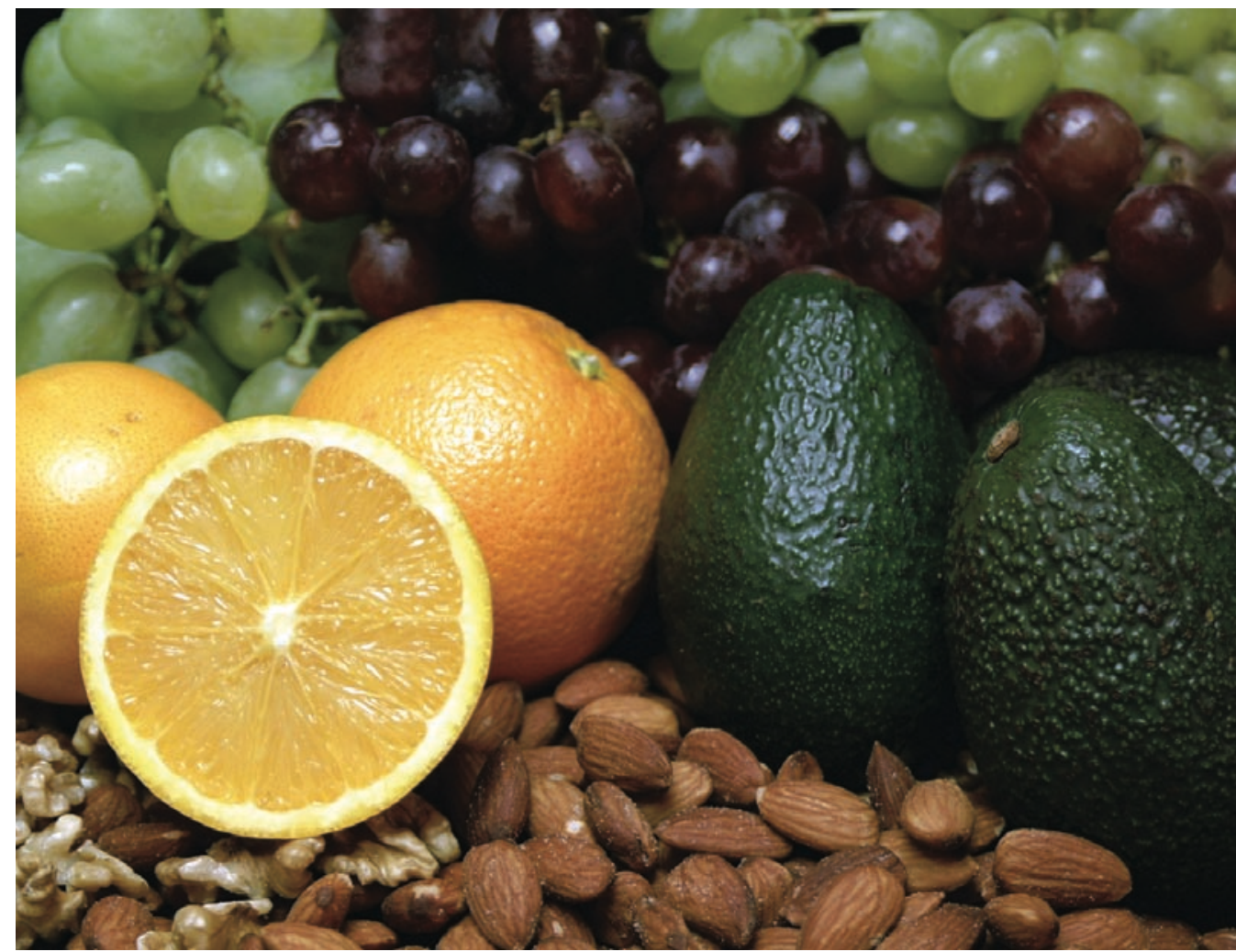

A Livermore study modeled the effect of climate change on six perennial crops grown in California: wine grapes, almonds, table grapes, oranges, walnuts, and avocados.

the risks that climate change presents to

food production and the food security of society and what actions we can take to minimize those risks," says Lobell. "These concerns have received surprisingly little attention in the past. The climate expertise and computer resources at Livermore make it a great place to explore this issue."

About 11 percent of Earth's land surface is used to grow crops, and 40 percent of the world's food supply comes from the 2 percent of land that is irrigated. In California, agriculture is important to the state's economy, but changes in the industry would have repercussions far beyond the state's borders. As the nation's leading producer of nearly 75 different crops, California supplies more than half of all domestic fruit and vegetables. In fact, California is the sole national producer of both almonds and walnuts. It produces 80 percent of the world's almond crop and a high percentage of fruits, vegetables, and other nuts. Statewide, agricultural income from sales was $\$ 27.8$ billion in 2003, 13 percent of the U.S. total.

In a recent study, Lobell modeled the effect of climate change through 2080 for six of California's most valuable perennial crops: wine grapes, almonds, table grapes, oranges, walnuts, and avocados. "In California, 20 to 30 years is the productive lifespan for most of these plants," Lobell says. "If we can get a picture of how the climate will change during this interval, we can evaluate what that means in terms of the projected crop yields. In addition, keeping the time frame relatively short limits the uncertainty in the modeling results." 


\section{Lessons from the Archives}

For this study, Lobell and his colleagues used climate models developed by various research organizations throughout the world and stored at the Program for Climate Model Diagnosis and Intercomparison (PCMDI) in Livermore's Energy and Environment Directorate. PCMDI develops methods and tools for comparing the many general circulation models (GCMs) used to simulate the global climate. In addition, PCMDI stores terascale data sets from GCM simulations, making them available to climate scientists worldwide. (For information about recent global climate change simulations, see $S \& T R$, June 2006, pp. 25-27.)

Lobell and his colleagues selected climate projections from 22 coupled ocean-atmosphere GCMs, which simulated future scenarios of greenhouse-gas emissions at medium-high, medium,

(a)
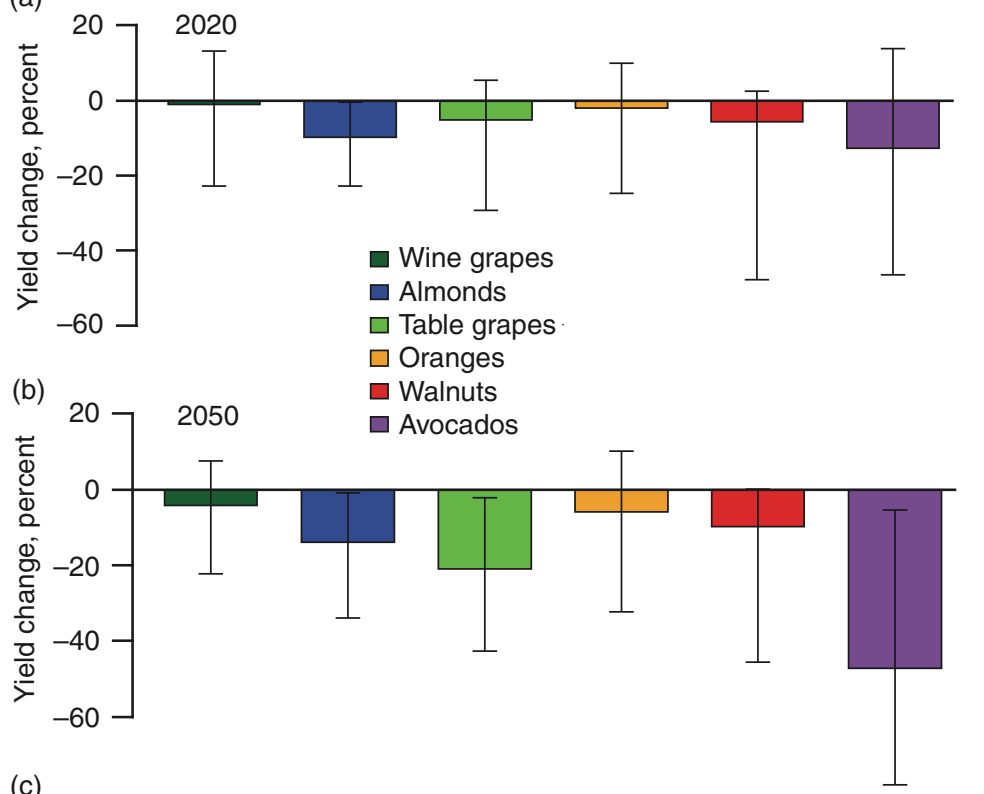

(c)

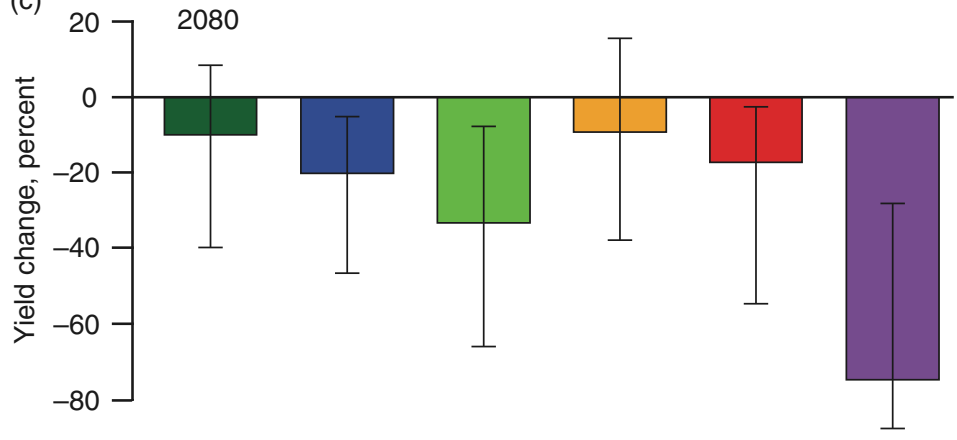

Results from the Livermore simulations of climate and crop yield show the median projected change for six California crops by (a) 2020, (b) 2050, and (c) 2080. Error bars indicate the model uncertainty. Although the level of uncertainty is substantial, the overall trend is for decreased yields. and low levels. Those results were combined with the team's models of crop yield responses, which are based on records of crop yields and weather throughout California since 1980.

\section{Models Bear Fruit}

The projections show variable results for the six perennials studied. Wine grape yields, for instance, changed very little over the next century, but the other crops exhibited moderate to substantial declines in yield. The amount of uncertainty in the results was considerable, but the overall trend was for a decrease in yields. "More than 95 percent of the simulations for almonds, table grapes, walnuts, and avocados showed a negative response to warming by mid-century," says Lobell. "The current climate is either at or above the optimum temperatures for the crops we studied, and all climate models project at least some warming during this period. Also, these crops are irrigated, so the uncertainties in precipitation projections, although large, have a relatively minor effect on the simulations. Of course, these projections assume that precipitation changes do not affect the availability of irrigation water, which is a fairly safe assumption for these high-value fruits and nuts but likely not for other crops."

Lobell notes that many factors were missing from the study. For example, research indicates that elevated levels of atmospheric carbon dioxide can enhance plant production, at least for a time. Scientists generally believe that, with cereal crops, higher carbon dioxide levels will counteract increases in temperature of up to $2^{\circ} \mathrm{C}$, the amount of warming that most simulations project will occur by 2050 . Beyond that, the warming effect dominates, and crop yields decrease. Scientists have yet to determine whether perennial crops will respond in the same manner.

\section{Beyond the Archives}

Another issue is that, historically, climate models have not performed well in agricultural regions. Many scientists, including Lobell and Livermore researchers Philip Duffy and Celine Bonfils, are investigating whether the accuracy of regional simulations is affected by farming activities. Global climate models tend to focus on factors that affect the entire planet, such as greenhouse gas levels. At a regional level, however, local activities such as frequency of tilling, crop selection, and amount of irrigation may be important factors in a simulation.

In examining historical data on weather and irrigation changes, Lobell and his colleagues found that irrigation has significantly reduced temperatures in specific agricultural areas in California. This cooling occurs because moisture evaporates into the atmosphere and absorbs energy that otherwise would go into heating the land. Lobell also ran climate simulations to evaluate the interaction of irrigation with greenhouse gases. Without irrigation included, models indicate that most agricultural areas become drier and warmer as greenhouse gas levels increase, with regional 
temperatures rising 4 to $5^{\circ} \mathrm{C}$ when carbon dioxide levels are doubled. The reality, however, is that farmers will likely maintain the soil's moisture level by irrigating their crops. When this water is included in simulations, the temperature increase is only 3 to $4^{\circ} \mathrm{C}$.

\section{What Now?}

Climate change models can also be used to evaluate options for adapting to the new climate. For example, Lobell simulated future yields of perennial crops by county to determine if production could be effectively shifted to more favorable areas. Models of today's climate indicate that much of the current crop area is in counties with the highest simulated yields - that is, farmers have selected good regions for each crop, and the varieties of plants are suitable to the regions. However, with an increased warming of $2^{\circ} \mathrm{C}$, the models project that no county in California can produce walnut yields at 95 percent of the current state average. Projections for almonds, (a)

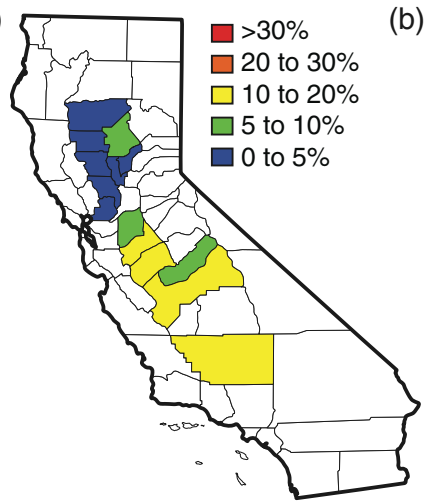

(c)

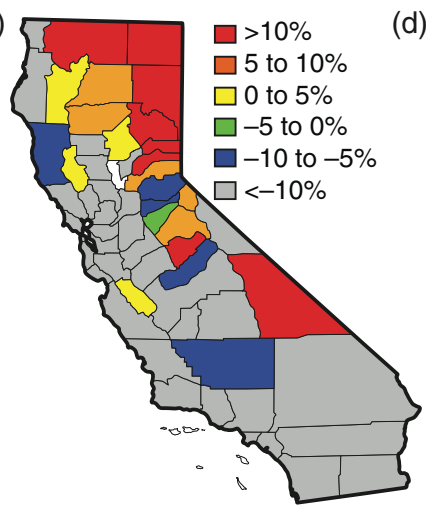

(b)

(d)
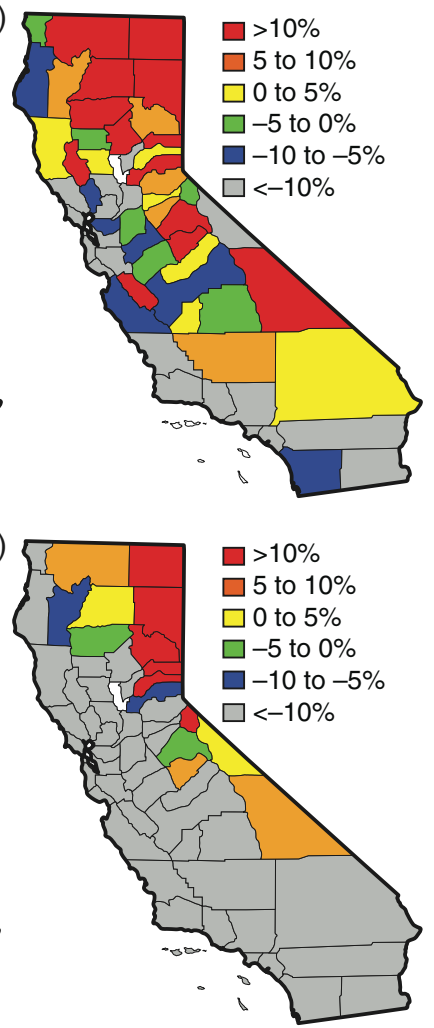

The Livermore climate-crop models can examine options for adapting to a warmer climate. For example, simulations can project almond yields by county, allowing decision makers to consider new locations for future planting. (a) The current area of California almond crops is shown as a percentage of the state's total area. The projected yield for each county (expressed as a percentage of the current statewide average yield) shows options for crop locations given (b) the current climate, (c) $2^{\circ} \mathrm{C}$ warming, and (d) $4^{\circ} \mathrm{C}$ warming. table grapes, and avocados grown in a climate $2^{\circ} \mathrm{C}$ warmer show some areas in the state that would be appropriate to keep yields near or even above current levels. However, these regions are not close to the current growing areas, and shifting production to new areas could be difficult and expensive.

Yields decrease even more when warming reaches $4^{\circ} \mathrm{C}$, as do the areas with high-yield potential. These changes are particularly noticeable for oranges, walnuts, and avocados. Still, opportunities may exist to shift production. "The feasibility of relocating crops depends on many factors, such as topography, soils, irrigation infrastructure, transportation infrastructure, and competing land uses," says Lobell. "Making these adaptations a reality will require climate scientists and agricultural decision makers working together."

Lobell is conducting similar studies for regions with crops of more direct relevance to food security, such as wheat, rice, and corn. A recent study concluded that climate change is already having a negative effect on the global production of wheat and corn. The overall goal of this research is to better understand the relationship of climate and agriculture so that informed decisions can be made about crop management and agricultural investments. "In the current world, more than 20,000 people die every day from causes related to hunger and poverty," Lobell says. "With climate change, the number of deaths could double or increase even more. If we can better understand the risks we face and evaluate our options for dealing with these changes, we can decide how much time and money to spend on the problems and what actions we can take to improve our trajectory."

—Ann Parker

Key Words: agriculture, California, climate change, food supply, global warming, land use, perennial crops, Program for Climate Model Diagnosis and Intercomparison (PCMDI).

For further information contact David Lobell (925) 422-4148 (lobell2@IInl.gov). 
Research Highights

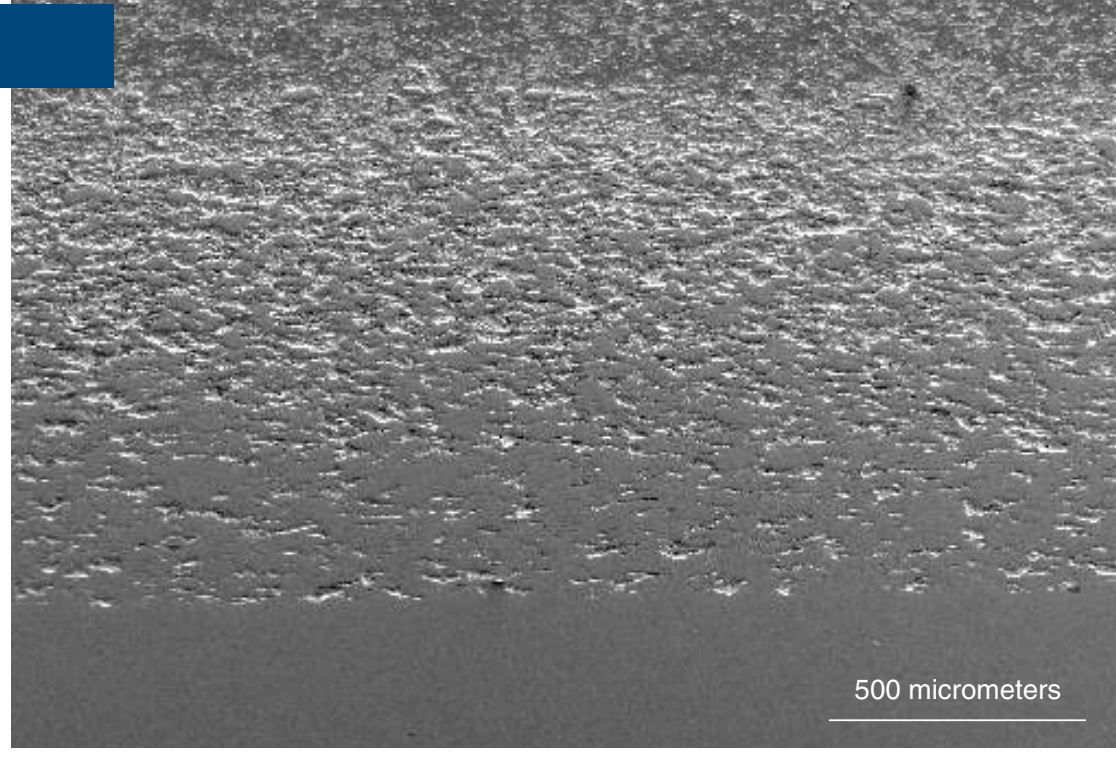

\section{New Routes to High Temperatures and Pressures}

A micrograph of a functionally graded material impactor in cross section reveals its constituent layers (magnified). The image depicts a smooth transition in density from one layer to the next between each of the five layers shown.

\begin{abstract}
EOR several decades, Lawrence Livermore physicists have been among the scientific leaders investigating the properties of material under high temperatures and pressures. Such experiments help them fully understand how material behavior changes at the extreme conditions that occur in a nuclear detonation or a planet's interior. For example, in 1996, Livermore researchers used one of the Laboratory's two-stage light-gas guns to shock-compress hydrogen to its metallic state, a form of the element believed to be prevalent in Jupiter. (See $S \& T R$, September 1996, pp. 12-18.)

Using various experimental platforms such as gas guns, lasers, magnetic accelerators, and diamond anvil cells, they can conduct experiments as close as possible to the desired pressures and temperatures and extrapolate the results to the conditions they want to investigate. A problem with these techniques is that researchers cannot examine the full range of material behavior as conditions change. Each platform yields slightly different but complementary information about the material being studied.

For example, typical shock-wave experiments on gas guns or lasers measure the Hugoniot, a particular relationship of pressure to density for a single shocked state. Lasers and magnetic accelerators can be used to study the principal quasi-isentropes, which represent the pressure-density relationship of materials at nearly constant entropy (a measure of the system's randomness or of irreversible work). In contrast, diamond anvil cells provide insight into material behavior on an isotherm or isobar, the pressure-density behavior at constant temperatures or pressures. (See $S \& T R$, December 2004, pp. 4-11.)

All of these techniques provide valuable information, but each one is limited to a specific thermodynamic path: a Hugoniot, a quasi-isentrope, or an isotherm. Realistic materials and conditions do not occur along only one thermodynamic path but within a range of conditions. Extrapolating data between these constraints introduces uncertainties into the computer models used to simulate extreme environments. For instance, the temperature at a given
\end{abstract}

pressure on the Hugoniot curve is higher than the temperature at the same pressure on a quasi-isentrope. In addition, the strain rates, or rates of compression, produced in shock experiments can vary as much as 10 orders of magnitude from those produced in quasistatic diamond anvil cell experiments.

To address this problem, physicists Jeff Nguyen, Daniel Orlikowski, and Neil Holmes have developed an experimental approach to study the exact conditions at which materials exist. Their technique uses multilayered functionally graded material (FGM) impactors (also called graded density impactors) in gasgun experiments to simulate conditions that were previously inaccessible in a precisely controlled laboratory environment. Impactors are the projectiles a gas gun launches toward its target. With FGM impactors, data from a set of continually varying experiments can be used to create models of material behavior, say, along a path to a planet's core. Scientists no longer need to compare extrapolated data from several experiments conducted at disparate pressures and temperatures. The new impactors also increase design flexibility so that experiments are not constrained to one thermodynamic path.

\section{Building Multilayered Impactors}

More than 20 years ago, gas-gun experiments designed to achieve quasi-isentropic compression used impactors composed of several layers of different materials with increasing density. Experiments with these impactors created a modest shock, followed by a series of small steplike pressure increases.

Nguyen's team solved the problems of the initial shock and step-wise pressure increases with a rudimentary powder technique. The FGM impactors designed by Nguyen's team are discs with as many as 100 or more layers, each less than 30 micrometers thick (roughly equivalent to half the thickness of a sheet of paper). As 
the number of layers increases and the thickness of any particular layer decreases, the behavior of the observed pressure increases changes from steplike to continuous.

Livermore technician Eamon Loughnane built the first impactors by hand to demonstrate the flexibility of the FGM technique. In early experiments with these prototypes, density ranged from 0.1 to more than 10 grams per cubic centimeter. With the tape-casting technique developed by Laboratory engineer Peter Martin, the level of reproducibility and planarity improves to within 1 to 2 percent.

Now, impactors that create nearly continuous pressure profiles can be rapidly fabricated using advanced powderprocessing techniques such as tape casting. In this process, individual layers are prepared from powdered metals such as copper, magnesium, and tungsten. The metal powders are mixed with an organic solvent, plasticizers, and binders to form a slurry, which is then cast onto a Mylar film. After drying, the tapes are smooth and flexible.

Tapes with different densities can be commercially prepared in advance, and a tape's composition can be tailored to provide specific properties. To fabricate an FGM impactor, technicians punch circular discs from different rolls of tape and stack them in the precise order determined for an experiment. The stacked tapes are laminated together, heated to remove the organic plasticizers and binders, and hot pressed to increase the density of the metal powders.

By carefully selecting the different layers for an FGM impactor, an experimenter can design the density profile for each experiment. For example, a series of impactor layers with increasing density imparts a compressive force, while a series of layers with decreasing density creates a controlled release of pressure. An abrupt increase in density from one layer to the next can be used to generate a shock wave. An FGM impactor made of up to 100 different tapes provides an unprecedented level of control of the temperature and pressure conditions. Thus, researchers can combine a powerful shock, quasiisentropic compression, controlled pressure release, and periods of continuous pressure, all in one experiment. The currently achievable densities with the tape-casting technique range from 1.7 to 9 grams per cubic centimeter. Nguyen's team is working to extend this capability for a density range from 0.1 to about 15 grams per cubic centimeter.

\section{Experiments Validate the Approach}

The Laboratory Directed Research and Development Program initially funded the FGM impactor research, which was proposed by Nguyen, Holmes, and physicist Fred Streitz. Orlikowski and Martin later joined the team along with physicist Reed Patterson and engineer Ryan Krone.

In the past six years, Nguyen's team has conducted more than 125 experiments using the FGM impactors on Livermore's light-gas guns. The researchers have analyzed the performance of the FGM impactor, obtained the equation of state (EOS) of tantalum and aluminum, and probed the strength of solid aluminum and the strain-rate effects of twinning (a form of deposition) in copper. They also have examined the liquid-to-solid phase transitions in bismuth and water and made novel materials.

In the gas-gun experiments, an FGM impactor, 3 to 8 millimeters thick and about 3 centimeters in diameter, hits its target at velocities of 1 to 8 kilometers per second. Solid targets are typically disks with thicknesses up to 5 millimeters, attached to a 10-millimeter-thick single crystal of transparent lithium fluoride. Measurements are usually made of the particle velocity of the material undergoing compression, which is recorded at the target-lithium fluoride interface by a diagnostic system called VISAR (velocity interferometer system for any reflector). In addition, an ellipsometer, which measures the polarization of light reflected from the target, can be used to provide information on the changing structure of a solid metal under pressure. Recovered samples can also be analyzed by such techniques as scanning electron microscopy and Vickers hardness testing.

Experimental observations are compared with simulations developed by Orlikowski using Livermore's CALE code. According to Orlikowski, the simulations have accurately modeled the experimental results. Models also guide researchers in designing the gas-gun experiments and choosing the impactor layers.

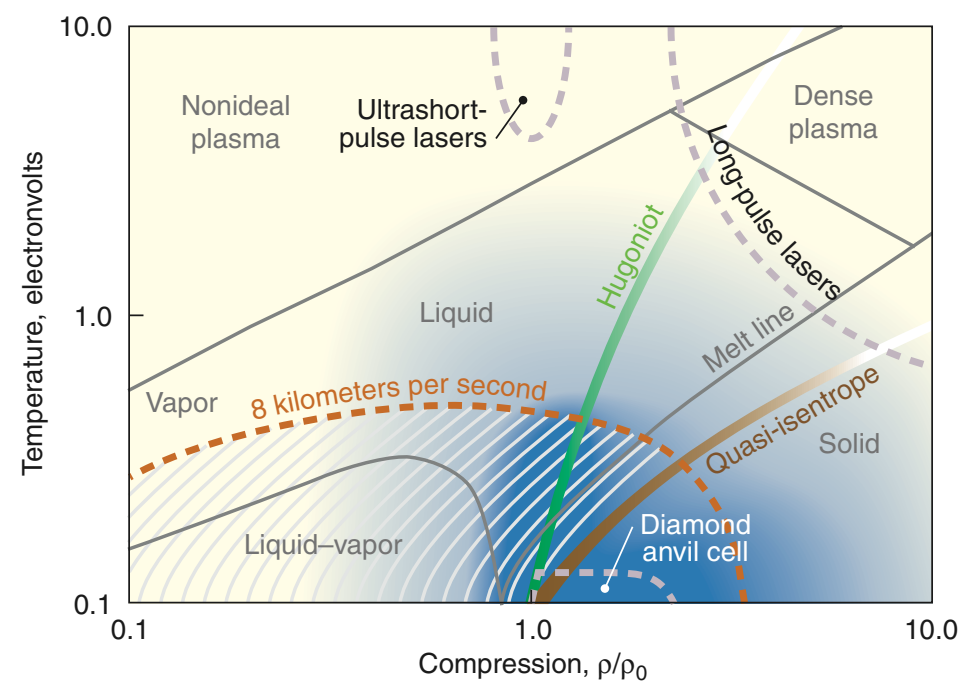

Experiments using long- and ultrashort-pulse lasers, diamond anvil cells, and gas guns access different regions of high temperature and pressure, or compression, where materials can change phase. Gas-gun experiments using Livermore's functionally graded material impactors can record measurements in continuous areas (hatched) that are not accessible with traditional techniques. Blue indicates the level of understanding from high (dark) to low (light). 


\section{A New Class of Experiments}

With the greater flexibility offered by today's FGM impactors, researchers can design experiments that address precise questions about material behavior. For planetary studies, they can recreate the exact conditions of a planetary isentrope, which is hotter than a principal isentrope, by shocking the sample to a temperature-elevated state before the sample is quasi-isentropically compressed. To study the boundary between material phases, they are no longer constrained to data on the Hugoniot, isentrope, or isotherm. Instead, they can look at the exact temperatures and pressures of the phase transitions.

The team's experiments are helping scientists better understand the dynamic response of materials, including the kinetics of phase transitions occurring at high temperatures and pressures in nonequilibrium situations. Phase diagrams produced by FGM impactors can then be compared with those obtained using traditional methods. In one series of experiments, Nguyen's team

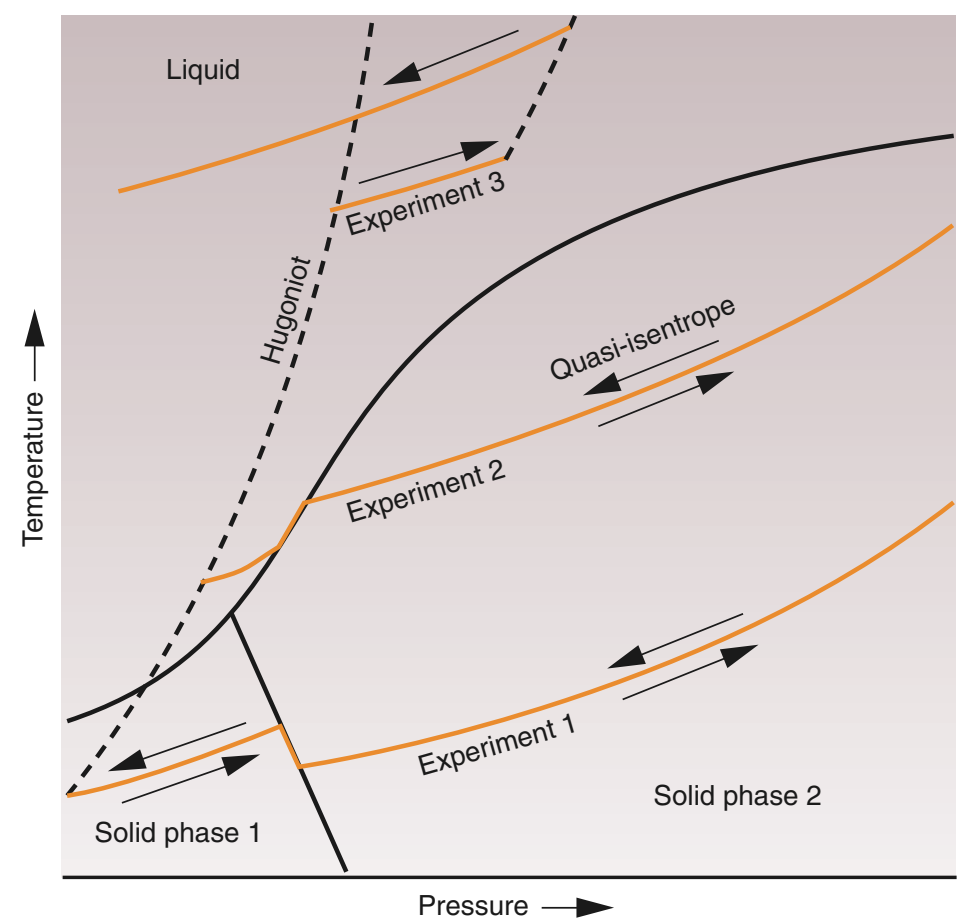

Functionally graded material impactors allow researchers to examine material behavior within a range of extreme pressures and temperatures. In hypothetical experiment 1, a solid in one phase is quasi-isentropically compressed into a solid of a different phase, or crystal structure, and released back into the original phase. In experiment 2 , a solid is shocked to its liquid phase and then quasi-isentropically compressed into a solid phase. In experiment 3 , a solid is shocked into a liquid and then isentropically compressed while remaining a liquid. It is then shocked again and released to a lower pressure state. quasi-isentropically compressed liquid bismuth and liquid water, separately converting both to solids. A simple shock on a liquid bismuth sample imparts an overly significant amount of energy (more than quasi-isentropic compression) to the sample, which prohibits solidification. Similar experiments with water produced a phase transition from liquid water to ice at elevated temperatures normally associated with the liquid phase.

The team is also using the FGM impactor to measure the principal quasi-isentrope for an EOS study. Another set of impactors will be used to create strain rates that fall between the capabilities of the traditional experimental techniques. These impactors are tailored to the compression (strain) rates obtained in magnetic accelerator and laser experiments. Data from the different techniques will be compared to examine strain-rate effects.

In addition, Nguyen's team is evaluating a metal's strength through a sequence of shock, compression, and then controlled release. Data from these experiments can be used to improve the fidelity of material strength models and thus help scientists better understand how metals respond to extreme conditions. The team is also collaborating with physicist James McNaney to examine how strain rate affects high-pressure twinning in copper. A research project with physicist Eduardo Bringa is studying superhard materials.

The experimental approach is being extended to the Joint Actinide Shock Physics Experimental Research (JASPER) Facility at the Nevada Test Site. Experiments with the JASPER gas gun will improve scientific interpretations of EOS measurements and predictions of phase behavior and material strength. In fact, Nguyen and his colleagues received a Defense and Nuclear Technologies Directorate award for their work in support of JASPER experiments. "We are accessing new regions of phase space by designing virtually any combination of shock, release, quasi-isentropic compression, and static pressure," says Nguyen. "We're controlling experiments to a degree never thought possible."

- Arnie Heller

Key Words: diamond anvil cell, equation of state (EOS), functionally graded material (FGM) impactor, graded density, Hugoniot curve, Joint Actinide Shock Physics Experimental Research (JASPER) Facility, quasiisentropic compression, two-stage light-gas gun.

For further information contact Jeff Nguyen (925) 423-6838 (nguyen29@IInl.gov). 


\section{From sound Waves to Stans Teller's Contributions to Shock Physics}

January 15, 2008, marks the 100th anniversary of Edward Teller's birth. This highlight is the first in a series of 10 honoring his life and contributions to science.

T HROUGHOUT his career, Edward Teller displayed a genius for building bridges of discovery between basic and applied science. In the field of shock physics, papers bearing his name are on both sides of the bridge.

Shock physics is the study of the behavior of materials as a sharp jump in density passes through them. The shock can be generated on any scale-from the action of a supernova to an earthquake, a hammer blow, or even a single photon. The material affected can vary as well-from the substance of stars at high energy density to matter under terrestrial conditions.

Teller's initial interest in shock physics was a natural outgrowth of his work on the quantum dynamics of atoms and molecules. In 1936, Teller and Soviet physicist Lev Landau coauthored a paper proposing a theory about how a sound wave, which essentially is a very weak shock wave, dissipates in a molecular gas. The paper trail leads next to an unpublished but oft-cited paper written in 1941 by Teller and physicist Hans Bethe, "Deviations from Thermal Equilibrium in Shock Waves." This work describes the results from a study commissioned by the U.S. Army to examine how shock waves interact with gases. Their research, which took into account the microscopic properties of a shocked medium, proved influential to later studies in many areas, including the behavior of vehicles reentering the atmosphere.

From here, Teller's renown

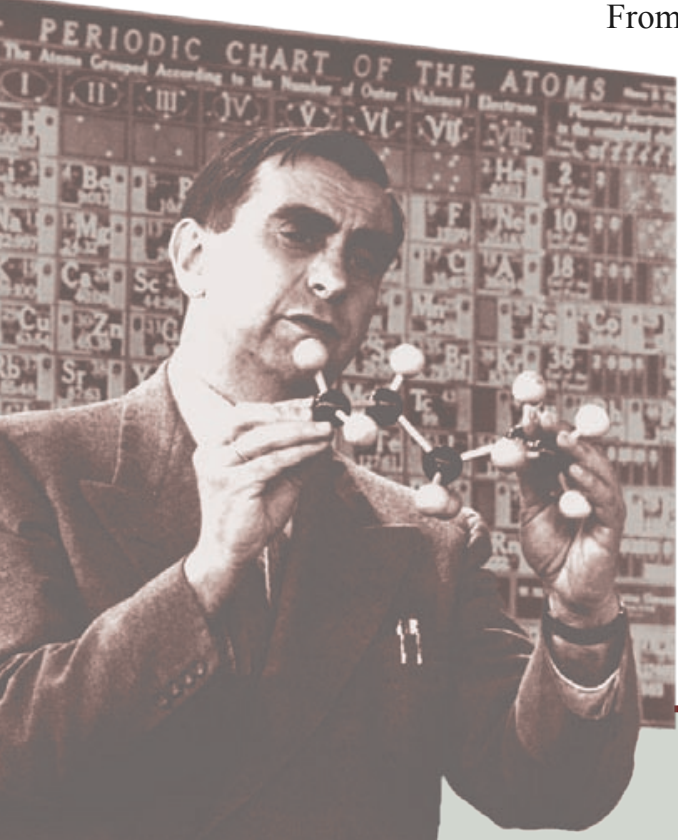
in the field began to grow. While lecturing at Columbia University, he was approached by Arthur Kantrowitz, a physics graduate student who also worked as an applied scientist at Langley Air Force Base. In his doctoral research, Kantrowitz had developed novel methods for measuring the thermal behaviors of shocks in gases. He asked Teller to sponsor his dissertation. In Memoirs, Teller says, "Arthur knew much more about the subject than I did. But when I started to demur . . . Arthur pointed out that my work with Landau, and a recent note that Bethe and I had published, made it impossible for me to deny all knowledge of the subject." Teller agreed to be his advisor and thus became a mentor in the arena of shock physics. Kantrowitz later became a leading expert in the field of hypersonic hydrodynamics.

When the discovery of fission was announced in 1939, Teller was intrigued and began to consider the potential uses of nuclear energy produced in both fission and fusion reactions. In 1942, he joined the Manhattan Project, to help develop the nation's first atomic bomb. From the beginning, shock physics was an important part of that research as scientists worked to understand how the shock waves produced by high explosives and nuclear energy release would affect the various materials being used in a nuclear weapon.

Teller's interest in high-energy-density physics and shock physics continued after the war. For example, in 1949, he coauthored the important paper "Magneto-Hydrodynamic Shocks" with physicist Frederick de Hoffman, generalizing shock "rules" to relativistic magnetohydrodynamics, which studies the interaction of density and magnetic-field pulses in

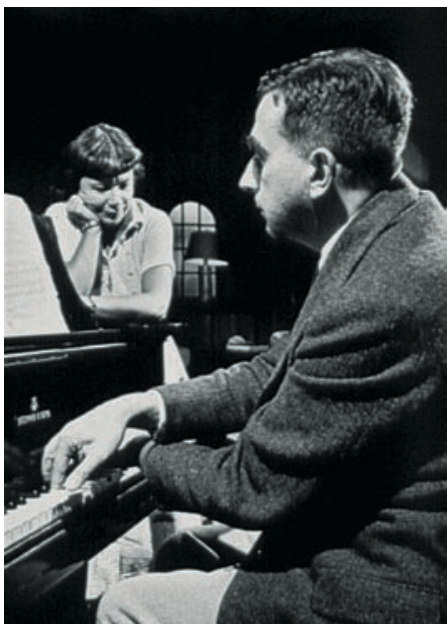

Edward Teller enjoyed playing the piano for his wife, Mici. (Photograph courtesy of Jon Brenneis.) electrically conducting liquids or gases, such as molten metal or plasma. Furthermore, Teller initiated significant work during and after the war on equation-of-state models, a key ingredient in understanding shock propagation.

It is not surprising then, given the shock physics thread weaving through his life at the intersection of basic and applied science, that Lawrence Livermore National Laboratory - the laboratory cofounded by Teller and Ernest O. Lawrence in 1952 - should become known for its shock physics experiments and 
the computer codes and simulations based on such data. Livermore's early shock physics experiments allowed scientists to study the behavior of gases, fluids, and solids as they are exposed to shock waves. High-fidelity data from these experiments improve the accuracy of simulations used to replicate past underground nuclear tests and thus are crucial to today's Stockpile Stewardship Program, which ensures the safety and reliability of the nation's nuclear weapons.

Shock physics continues to be an important research area at the Laboratory. Experimental platforms such as gas guns, lasers, and diamond anvil cells allow researchers to elucidate the equations of state of shocked materials and improve their understanding of complex materials such as plutonium. (See the article on p. 23.) In 1994, shock experiments at Livermore yielded the first observation of fluid metallic hydrogen. Using gas guns and lasers, Livermore scientists produce shocks that create extraordinarily high pressures, mimicking the extreme conditions in an explosion, the detonation
Results from Livermore's three-dimensional hydrodynamics model of a red giant star show that, deep in the star's interior, hydrogen-rich clouds (red) float above the hydrogen-burning shell (blue).

of a nuclear weapon, an inertial fusion experiment, a star, or the impact of a large meteorite, were one to hit the Earth. Shock physics experiments helped determine the melting point for iron in Earth's core, while data about hydrogen and other molecular fluids such as water are allowing scientists to better understand the interiors of giant planets in our solar system.

Whether it was defining the interactions of sound waves with gases or exploring the behavior of metals under extreme conditions, Teller excelled at making connections between theory and applied science, including the field of shock physics. This approach - taking what is known and what can be done, and pushing beyond - is one that continues at Lawrence Livermore to this day.

-Ann Parker

Key Words: Edward Teller, magnetohydrodynamics, Manhattan Project, shock physics.

For further information contact Stephen B. Libby (925) 422-9785 (libby1@IInl.gov).

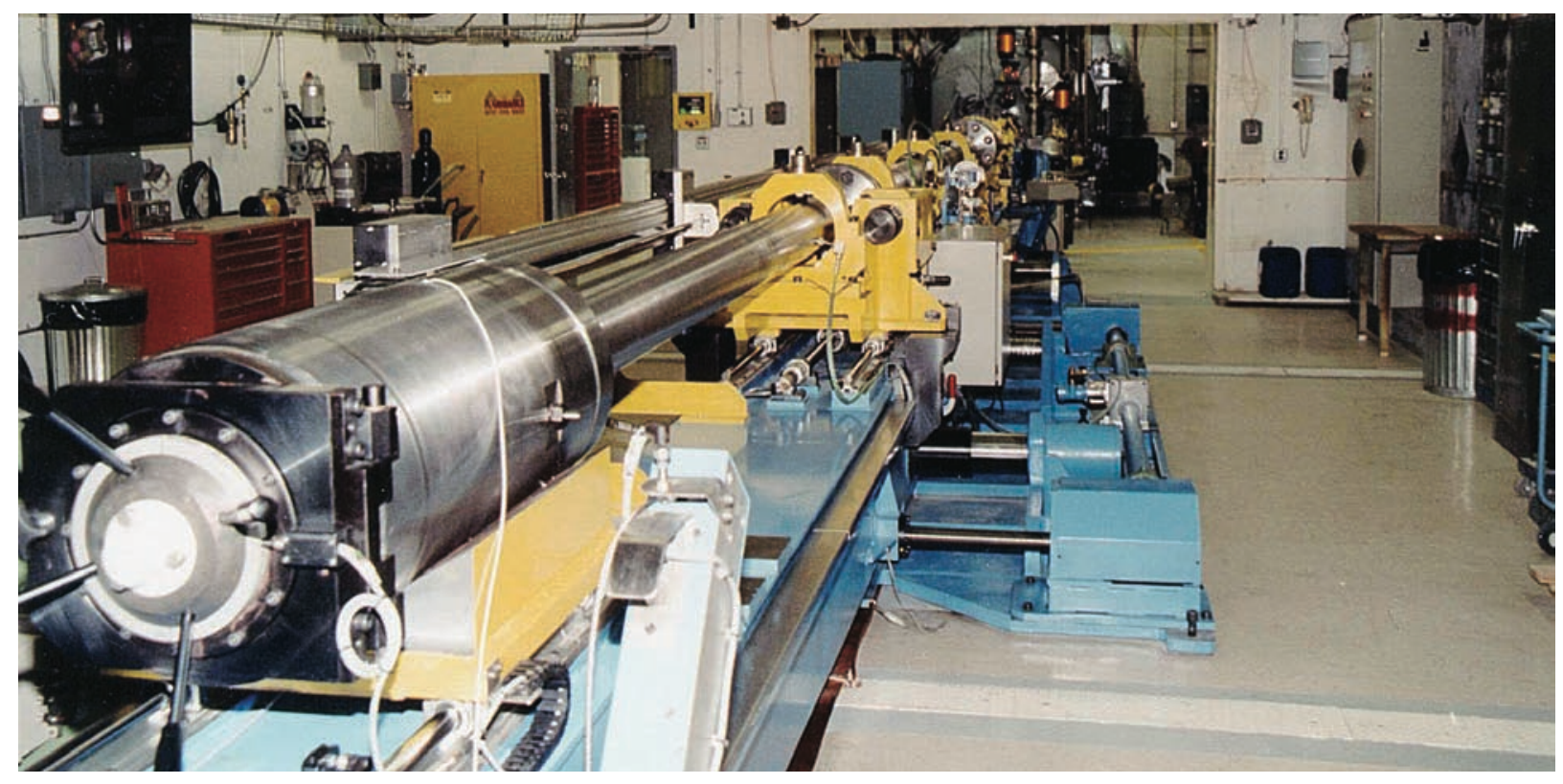

The two-stage gas gun at the Joint Actinide Shock Physics Experimental Research Facility in Nevada is one method used to perform shock physics experiments. (Photograph courtesy of the Nevada Test Site.) 


\section{Patents}

Fiber Optic Gap Gauge

Billy E. Wood, Scott E. Groves, Greg J. Larsen, Roberto J. Sanchez

U.S. Patent $7,134,219$ B2

November 14, 2006

A small, lightweight gauge with high sensitivity can indirectly determine the displacement or absolute gap width by measuring the axial strain orthogonal to the displacement or gap. The gauge's base, preferably made of titanium, has a central tension bar. Springs connect opposite ends of this bar to a pair of end connector bars. An elongated bow spring connected to these connector bars has a middle section that bows away from the base, producing an axial strain to define a gap. A strain sensor, such as a Fabry-Perot interferometer, measures this strain, which is proportional to the displacement of the middle section and thus indirectly provides a measurement of axial strain.

\section{Drum Ring Removal/Installation Tool}

\section{William Andrew Andrade}

U.S. Patent $7,134,174$ B1

November 14, 2006

This handheld tool, or a pair of such tools, can be used to remove or install a bolt-type clamping ring on a container barrel or drum. The clamping ring has a pair of clamping ends, each with a throughbore. The tool has an elongated handle with an elongated lever arm transversely connected to one end. The lever arm can be inserted into a throughbore and leveraged with the handle to exert a first moment on the selected clamping end. A second lever arm, such as a socket with an open-ended slot, is suspended alongside the first lever arm. It, too, can engage the clamping end and, with the handle, exert a second moment orthogonal to the first moment. In this manner, the first and second moments hold the end in a fixed position so that the clamping end may be controlled with the handle. Two independently controlled tools may be used simultaneously on a pair of clamping ends to contort the geometry of the drum clamping ring so it can be installed or removed.

Flexible Electrode Array for Artificial Vision

Peter Krulevitch, Dennis L. Polla, Mariam N. Maghribi, Julie Hamilton U.S. Patent $7,146,221$ B2

December 5, 2006

In this artificial vision system, an image is captured or otherwise converted into a signal that is transmitted via an implant to the retina. The implant consists of a polymer substrate made of a compliant material such as poly(dimethylsiloxane) that conforms to a retina's shape. Electrodes and conductive leads embedded in the substrate transmit a signal to the cells in the retina, and this signal, which represents the image, stimulates the cells.

\section{Awards}

Livermore researchers Robert Budnitz and Karl van Bibber have been named fellows of the American Association for the Advancement of Science.

Budnitz was selected in the engineering section for distinguished contributions to understanding the safety of nuclear power reactors and deep geologic radioactive waste repositories, with emphasis on probabilistic safety analysis. Budnitz has worked on nuclear power reactor safety for 30 years. He joined the Laboratory in 2002 as part of the Energy and Environment Directorate.

Van Bibber was elected in the physics category for distinguished contributions to the field of astrophysics and particle accelerator physics, particularly for his efforts in the search for dark matter axions. A Livermore employee for 21 years, van Bibber is deputy director of the Laboratory Science and Technology Office.

The American Physical Society (APS) has selected two Laboratory employees as APS fellows. Peter Amendt, who works in Livermore's Defense and Nuclear Technologies Directorate, was honored for "seminal contributions to the development of indirectly-driven single- and double-shell inertial confinement fusion physics necessary for the demonstration of laboratory-scale ignition." Gilbert (Rip) Collins, who works in the Physics and Advanced Technologies Directorate, was honored for "seminal contributions to the field of high-energy-density physics related to the development and application of novel laser-compression capabilities to measuring ultra-high pressure material properties."

Richard Christensen of the Materials Science and Technology Division received the Nadai Medal, one of the highest awards in mechanical engineering presented by the American Society of Mechanical Engineers (ASME). Christensen, who recently retired from the Laboratory, was honored for his "outstanding contributions to mechanics of materials and heterogeneous media, theory of viscoelasticity, properties of polymers and nonNewtonian rheology and wave propagation."

The Nadai Medal recognizes "significant contributions and outstanding achievement which broaden the field of materials engineering." ASME established the award in 1975 to honor Arpad L. Nadai, a pioneer in the field of engineering materials who made important contributions in the area of plasticity.

The Terascale Simulation Facility (TSF) Project received the Project Management Award of Achievement, which is given annually by the Secretary of the Department of Energy for outstanding performance based on overall management and successful completion of a project. TSF houses the Laboratory's world-class supercomputers and includes office space for more than 250 employees. The 23,504-square-meter facility was completed in late 2004, eight months ahead of schedule and $\$ 1.2$ million under budget. 


\section{Advancing the Frontiers in Cancer Research}

Researchers from Lawrence Livermore and the University of California Davis Cancer Center are developing methods to detect the early stages of cancer and tailor treatment for cancer patients. One team is using time-of-flight secondary-ion mass spectrometry to image and classify individual cells on the basis of their mass spectra. The technique could potentially detect a single aberrant cell within a normal cell population and provide clues to single cell progression within carcinogenic and metastatic pathways. The Laboratory's accelerator mass spectrometer is being used to study the interaction of carboplatin, a drug commonly used in chemotherapy, with cancer cells. The studies may help physicians determine therapeutics for individual cancer patients. Another team is developing a compact proton accelerator that features a Livermore-designed dielectric insulator. The team's goal is to build a small machine to deliver the energy at a fraction of the cost of traditional proton therapy systems.

Contact: Jim Felton (925) 422-5656 (felton1@IInl.gov).

\section{On the Leading Edge of Atmospheric Predictions}

The National Atmospheric Release Advisory Center (NARAC) at Livermore predicts and maps the probable spread of hazardous materials released - either accidentally or intentionally - into the atmosphere. NARAC's models and codes are frequently updated to incorporate the latest computational and scientific capabilities. Considerable research and development focuses on simulating releases in complex urban environments. Outdoor and indoor dispersion models are being coupled, and the effects of the urban landscape are being incorporated into a weather forecasting program. NARAC researchers are also developing probabilistic methods that use field measurements to reconstruct atmospheric release events and determine an unknown source's location and size. Other projects are incorporating new capabilities into existing dispersion models, including the effects of high-altitude weather, rain, atmospheric chemistry, and surface roughness.

Contact: Gayle Sugiyama (925) 422-7266 (sugiyama1@IInl.gov). 
University of California

Science \& Technology Review

Lawrence Livermore National Laboratory

P.O. Box 808, L-664

Livermore, California 94551 